\title{
FITOPLÂNCTON DE UM RESERVATÓRIO EUTRÓFICO (LAGO MONTE ALEGRE), RIBEIRÃO PRETO, SÃO PAULO, BRASIL
}

\author{
SILVA, L. H. S. \\ Laboratório de Ficologia, Departamento de Botânica, Museu Nacional, UFRJ, \\ Quinta da Boa Vista, CEP 20940-040, São Cristóvão, RJ \\ Correspondência para: Lúcia Helena Sampaio da Silva, Laboratório de Ficologia, \\ Departamento de Botânica, Museu Nacional, UFRJ, Quinta da Boa Vista, \\ CEP 20940-040, São Cristóvão, RJ \\ Recebido em 15/04/97 - Aceito em 09/10/98 - Distribuído em 30/06/99
}

(Com 141 figuras)

\section{ABSTRACT \\ Phytoplankton in an eutrophic reservoir (Lake Monte Alegre), Ribeirão Preto, São Paulo, Brazil}

The study aims at presenting the phytoplankton of a small eutrophic reservoir, located in the Southeast of Brazil, based in samples fortnightly collected from April of 1988 to March of 1989 from one station located at the centre of the limnetic region. Ninety three species were identified, 9 varieties, 5 taxonomic forms, 9 taxa were determined at generic level and 3 were listed in their respective classes, in a total of 119 taxa belonging to 9 taxonomic classes (13 Cyanophyceae, 55 Chlorophyceae, 15 Zygnemaphyceae, 14 Euglenophyceae, 5 Bacillariophyceae, 3 Xanthophyceae, 6 Chrysophyceae, 4 Cryptophyceae e 4 Dinophyceae). It was observed a considerable complexity in the floristic composition in the Lake Monte Alegre, as registered in relation to other tropical lakes and reservoirs, with a bigger dominance of the green algae $(59 \%)$. The phytoplankton species was used as one of the aspects for the trophic characterization of the environment.

Key words: floristic composition, phytoplankton, eutrophic reservoir.

\section{RESUMO}

Este trabalho teve por objetivo apresentar a flora planctônica de um pequeno reservatório eutrófico, localizado no Sudeste brasileiro, baseado em amostras coletadas quinzenalmente durante o período de abril de 1988 a março de 1989 em uma estação localizada no centro da região limnética. Foram identificadas 93 espécies, 9 variedades, 5 formas taxonômicas e 9 táxons determinados em nível genérico - 3 foram listados em suas respectivas classes, em um total de 119 táxons pertencentes a 9 classes taxônomicas (13 Cyanophyceae, 55 Chlorophyceae, 15 Zygnemaphyceae, 14 Euglenophyceae, 05 Bacillariophyceae, 3 Xanthophyceae, 6 Chrysophyceae, 4 Cryptophyceae e 4 Dinophyceae). Foi verificada uma considerável complexidade na composição florística, conforme registrado para outros lagos e reservatórios tropicais, com maior contribuição da divisão Chlorophyta (59\%). As espécies fitoplanctônicas foram utilizadas como um dos aspectos para a caracterização trófica do ambiente.

Palavras-chave: composição florística, fitoplâncton, reservatório eutrófico. 


\section{INTRODUÇÃO}

Trabalhos limnológicos em reservatórios assumem acentuada importância devido ao expressivo número de represas de construção, relativamente recente, construídas no Brasil e, particularmente, no Estado de São Paulo. A ecologia de represas e a qualidade das águas nos reservatórios estão, fundamentalmente, relacionados com os sistemas integrados que atuam na bacia hidrográfica, incluindo as múltiplas atividades humanas e seus impactos (Tundisi, 1985, 1986).

O lago Monte Alegre (Fig. 1) localiza-se no Campus da Universidade de São Paulo (21 ${ }^{\circ} 11^{\prime}$ S e 47 $43^{\circ} \mathrm{W}$ ), Município de Ribeirão Preto, Estado de São Paulo, a uma altitude de $500 \mathrm{~m}$. A região encontra-se no limite entre os climas tropical e tropical de altitude, com duas estações climáticas bem marcadas, uma seca e fria - maio a setembro - e outra quente e chuvosa - outubro a abril (Nimer, 1989). O reservatório, construído com finalidade ornamental em 1942, ocupa uma área de cerca de $0,07 \mathrm{~km}^{2}$ com profundidade máxima de $5 \mathrm{~m}$ e média de $2,9 \mathrm{~m}$. A flutuação anual do nível da água é pouco pronunciada ( $c a$. de $0,40 \mathrm{~m}$ ), não sendo controlada pelo homem, e o tempo de retenção de suas águas é, em média, de 45 dias, funcionando como um pequeno lago (Meschiatti et al., 1986; Arcifa et al., 1990).

A saída de água é superficial por 3 vertedouros e o reservatório sofre escassa influência do ribeirão represado, devido à sua vazão relativamente pequena $\left(0,0095 \mathrm{~m}^{3} \cdot \mathrm{s}^{-1}\right)$. O lago Monte Alegre é eutrófico (Meschiatti et al., 1986; Arcifa et al., 1990; Silva, 1995) e, de acordo com Lewis (1983), pode ser classificado como polimítico descontínuo quente, com estratificações mais prolongadas durante a primavera e o verão.

A vegetação, nas margens do lago, é predominantemente rasteira, formada por gramíneas, ervas, arbustos e plantas ornamentais. Próximo ao reservatório, encontram-se plantações de cana-deaçúcar, alternadas com plantações de sorgo na entressafra.

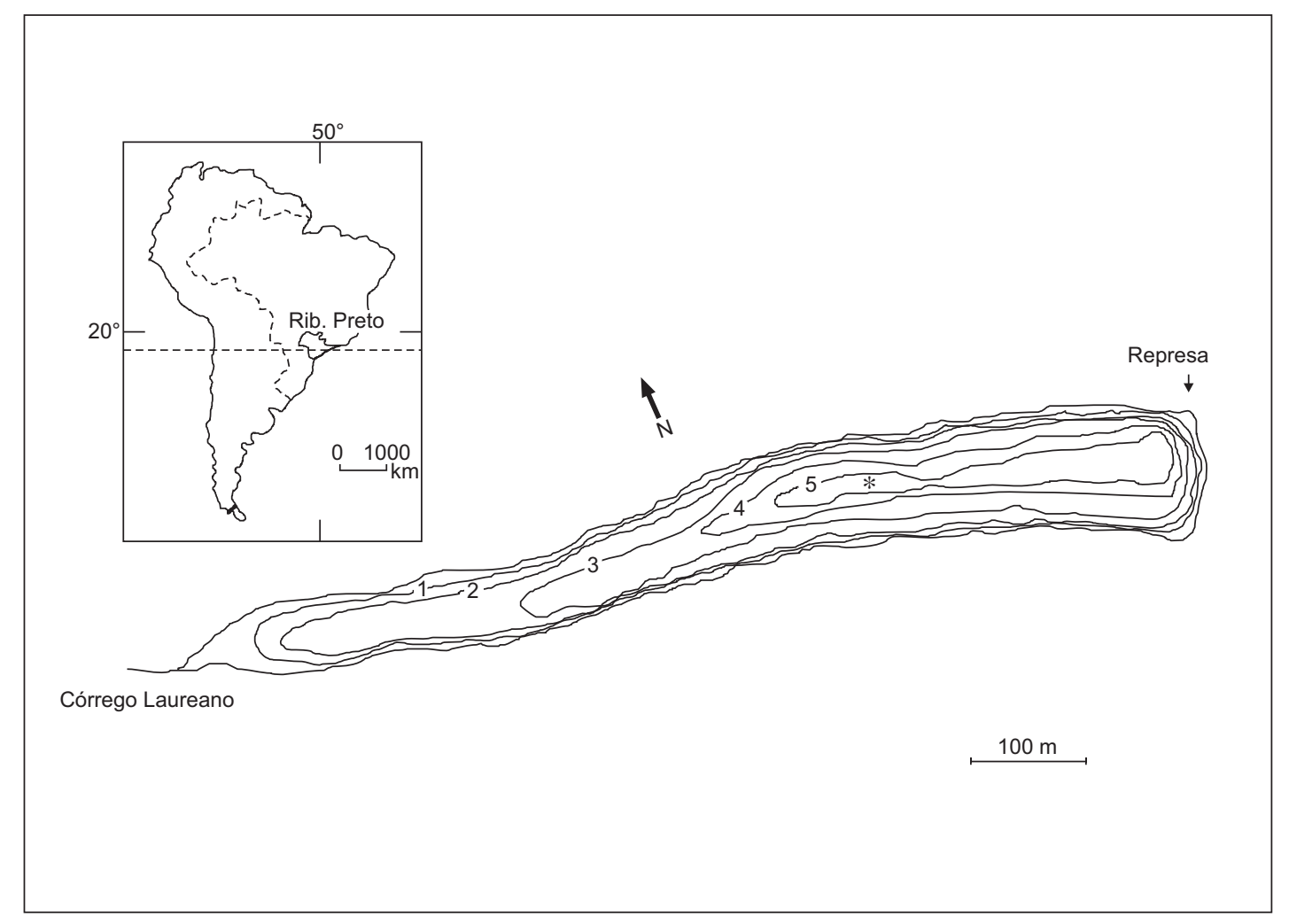

Fig. 1 - Localização e mapa do lago Monte Alegre assinalada a estação de coleta (*). 
O Reservatório Monte Alegre, objeto do presente estudo, tem sido estudado sob vários aspectos, como: estrutura térmica (Arcifa et al., 1990), zooplâncton (Arcifa et al., 1992; Silva, 1989), bactéria e protozooplâncton (Gomes, 1991), peixes (Arcifa \& Meschiatti, 1993; Arcifa \& Meschiatti, 1996), além de sua caracterização limnológica (Meschiatti et al., 1986; Godinho-Orlandi \& Arcifa, 1990; Silva, 1995).

O fitoplâncton tem sido estudado em diferentes aspectos, incluindo, além da composição florística, sua variabilidade temporal (Silva, 1995).

O presente trabalho teve por objetivo identificar a composição florística da comunidade fitoplanctônica; verificar a tendência observada para outros lagos e reservatórios da região Sudeste brasileira como a maior contribuição da divisão Chlorophyta (Marinho, 1994); analisar a complexidade de táxons e compará-la a outros ambientes tropicais, subtropicais e temperados; e utilizar os táxons identificados como um dos aspectos para a caracterização trófica do lago Monte Alegre.

\section{METODOLOGIA}

As amostras fitoplanctônicas foram coletadas quinzenalmente em uma estação central e em várias profundidades, na zona eufótica, através de garrafa de Ruttner. Em seguida, foram colocadas em um recipiente plástico e misturadas a fim de se obter uma amostra integrada. Subamostras de 250 $\mathrm{ml}$ foram fixadas com solução de lugol modificada (Vollenweider, 1974).

Para a identificação das populações, além das amostras quantitativas (Silva, 1995), foram utilizadas amostras coletadas com rede de plâncton de $25 \mu \mathrm{m}$ de abertura de malha e fixadas posteriormente com solução de Transeau.

Os táxons foram identificados analisandose as características morfológicas e morfométricas da vida vegetativa e reprodutiva, com base em bibliografia específica. Foram analisados em microscópio óptico Zeiss, modelo Standard 18, equipado com câmara-clara, medição, fotografia e contraste de fase.

A composição florística do ambiente de estudo foi comparada com a de outros lagos tropicais, subtropicais e temperados, sem levar em conta suas biomassas, sendo estas analisadas em Silva (1995). Os lagos e reservatórios utilizados para compa- ração com o lago Monte Alegre apresentaram tabulações completas de espécies, produzidas a partir de metodologias de coleta (método não-seletivo) e de análise (Utermöhl, 1958) semelhantes às utilizadas neste estudo.

Para a análise do grau de trofia do ambiente a partir das espécies fitoplanctônicas, foram utilizados os coeficientes propostos por Nygaard (1949):

- Coeficiente Simples:

$\mathrm{Q}=$ número de espécies de Chloroccocales/ número de espécies de Desmidiaceae se $\mathrm{Q}<1$ = lago oligotrófico e se $\mathrm{Q}>1=$ lago eutrófico

- Coeficiente Múltiplo ou Composto: $\mathrm{Q}=$ número de espécies (Cyanophyceae + Chloroccocales + Centrales + Euglenales) / Desmidiaceae

se $\mathrm{Q}<1$ = lago oligotrófico, e se $\mathrm{Q}>1$ = lago eutrófico

- Coeficiente de Diatomáceas:

$\mathrm{Q}=$ número de espécies de Centrales/número de espécies de Pennales

se $Q$ varia de 0,0 a $0,2=$ lago oligotrófico e se $Q$ varia de 0,2 a 3,0 = lago eutrófico

\section{RESULTADOS}

A comunidade fitoplanctônica do lago Monte Alegre, durante o período de estudo, esteve composta por 119 táxons pertencentes a 9 classes taxonômicas, sendo 13 Cyanophyceae, 55 Chlorophyceae, 15 Zygnemaphyceae, 14 Euglenophyceae, 5 Bacillariophyceae, 3 Xanthophyceae, 6 Chrysophyceae, 4 Cryptophyceae e 4 Dinophyceae (Fig. 2).

A seguir são apresentadas descrições e ilustrações dos 106 táxons identificados em níveis específicos e infra-específicos.

\section{Classe Cyanophyceae}

Aphanothece clathrata West \& West (Fig. 3)

Trans. R. Ir. Acad., 32, B, S. 111, pl. 10, Figs. 9-11, 1906.

Colônias de numerosas células cilíndricas; pseudovacúolos ausentes. Compr. das colônias 25$50 \mu \mathrm{m}$, larg. 10-20 $\mu \mathrm{m}$; compr. das células 1,5$2 \mu \mathrm{m}$, larg. $0,5-1 \mu \mathrm{m}$.

Chroococcus minor (Kütz.) Nag. (Fig. 4) 1849 .

Gatt. einzell. Algen, 5: 47, pl. 1A, Fig. 4, 


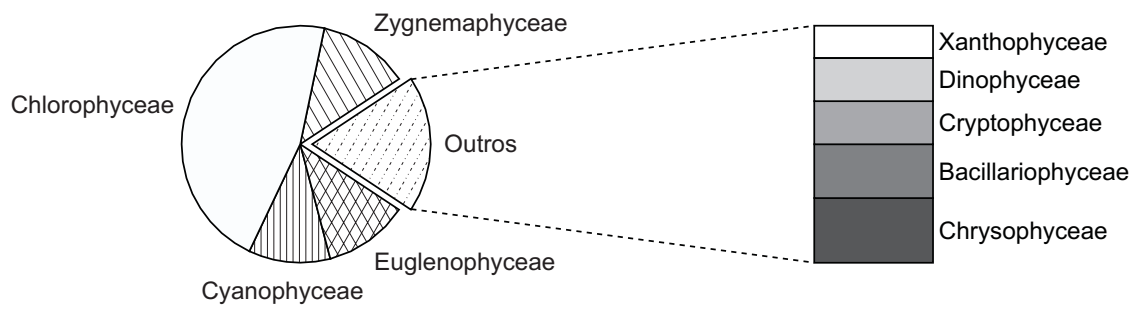

Fig. 2 - Contribuição percentual do número de táxons por classe taxonômica no lago Monte Alegre, no período de abril de 1988 a março de 1989.

Colônias com 1-2 células arredondadas; bainha mucilaginosa conspícua envolvendo cada célula. Compr. das células 1-2,5 $\mu \mathrm{m}$, larg. 1-2 $\mu \mathrm{m}$. 6)

Chroococcus minutus (Kütz.) Nag. (Figs. 5-

Gatt. einzell. Algen, 46, 1849.

Colônias com 2-4 células arredondadas; bainha mucilaginosa conspícua envolvendo cada célula. Compr. das células 4-4,5 $\mu \mathrm{m}$, larg. 4,5-5,5 $\mu \mathrm{m}$.

Lyngbya limnetica Lemm. (Fig. 10)

Bot. Zbl., 76: 154, 1898.

Filamentos retos; mucilagem delgada; células 1,3-1,6 vez mais longas que largas; septos não constrictos; célula terminal arredondada; conteúdo celular homogêneo. Compr. das células 1,5-2,5 $\mu \mathrm{m}$, larg. $0,5-1,5 \mu \mathrm{m}$.

Merismopedia tenuissima Lemm. (Fig. 7)

Bot. Zbl., 76: 154, 1898.

Colônias tabulares; 8-16-32 células subesféricas envoltas por bainha mucilaginosa. Compr. das células 1-1,5 $\mu \mathrm{m}$, larg. 1-2 $\mu \mathrm{m}$.

Microcystis aeruginosa Kütz. f. flos-quae (Wittr.) Elenk. (Fig. 8)

Monogr. Alg. cyanoph. pars spec., 1: 106, 1938.

Colônias esféricas ou alongadas; numerosas células esféricas; pseudovacúolos presentes. Diâm. das células 4,5-6 $\mu \mathrm{m}$.

Microcystis incerta (Lemm.) Lemm. (Fig. 9)

Abh. Naturw. Ver. Bremen, 17(5): 342, 1907.

Colônias esféricas; numerosas células esféricas; pseudovacúolos ausentes. Diâm. das células $0,5-1,5 \mu \mathrm{m}$.

Microcystis robusta (Clark) Nyg. (Fig. 11)

Dansk bot. Ark., 4(10): 8, Figs. 1-4, 1925.
Colônias esféricas ou alongadas; numerosas células esféricas; pseudovacúolos ausentes. Diâm. das células 5-6,5 $\mu \mathrm{m}$.

Oscillatoria boryana Bory ex Gom. (Fig. 12)

Annls Sci. nat., 16: 234, sér. 7, pl. 7, Figs. 22-23, 1892.

Tricomas retos ou quase, células $1,2-1,5 \mathrm{vez}$ mais largas que longas; septos transversais constrictos; célula terminal arredondada. Compr. das células 4,5-6 $\mu \mathrm{m}$, larg. 6-8,5 $\mu \mathrm{m}$.

Oscillatoria simplicissima Gom. (Fig. 13)

Annls Sci. nat., 16: 219, sér. 7, pl. 7, Fig. $1,1892$.

Tricomas retos ou quase, células 1,3-1,5 vez mais largas que longas; septos transversais nãoconstrictos; célula terminal arredondada. Compr. das células 3,5-5 $\mu \mathrm{m}$, larg. 5-7 $\mu \mathrm{m}$.

Oscillatoria subtilissima (Kütz.) ex Gom. (Fig. 14)

Annls Sci. nat., 16: 240, sér. 7, 1892.

Tricomas retos ou quase, células 2-2,5 vezes mais longas que largas; septos transversais nãoconstrictos; célula terminal arredondada; conteúdo celular homogêneo. Compr. das células 4-5 $\mu \mathrm{m}$, larg. 1,5-2,5 $\mu \mathrm{m}$.

Raphidiopsis mediterranea Skuja (Fig. 15)

Hedwigia, 77: 23, pl. 1, Fig. 5, 1937.

Tricomas isolados, retos, atenuados nas extremidades; células $2-2,5$ vezes mais longas que largas; septos não-constrictos; heterocistos e acinetos não observados. Compr. das células 5,5-7 $\mu \mathrm{m}$, larg. 2-3 $\mu \mathrm{m}$.

Synechocystis aquatilis Sauvag. (Figs. 16-17)

Bull. Soc. bot. Fr., 14: 121, pl. 6, Fig. 2, 1892.

Células isoladas, esféricas. Diâm. das células $4,5-5,5 \mu \mathrm{m}$. 

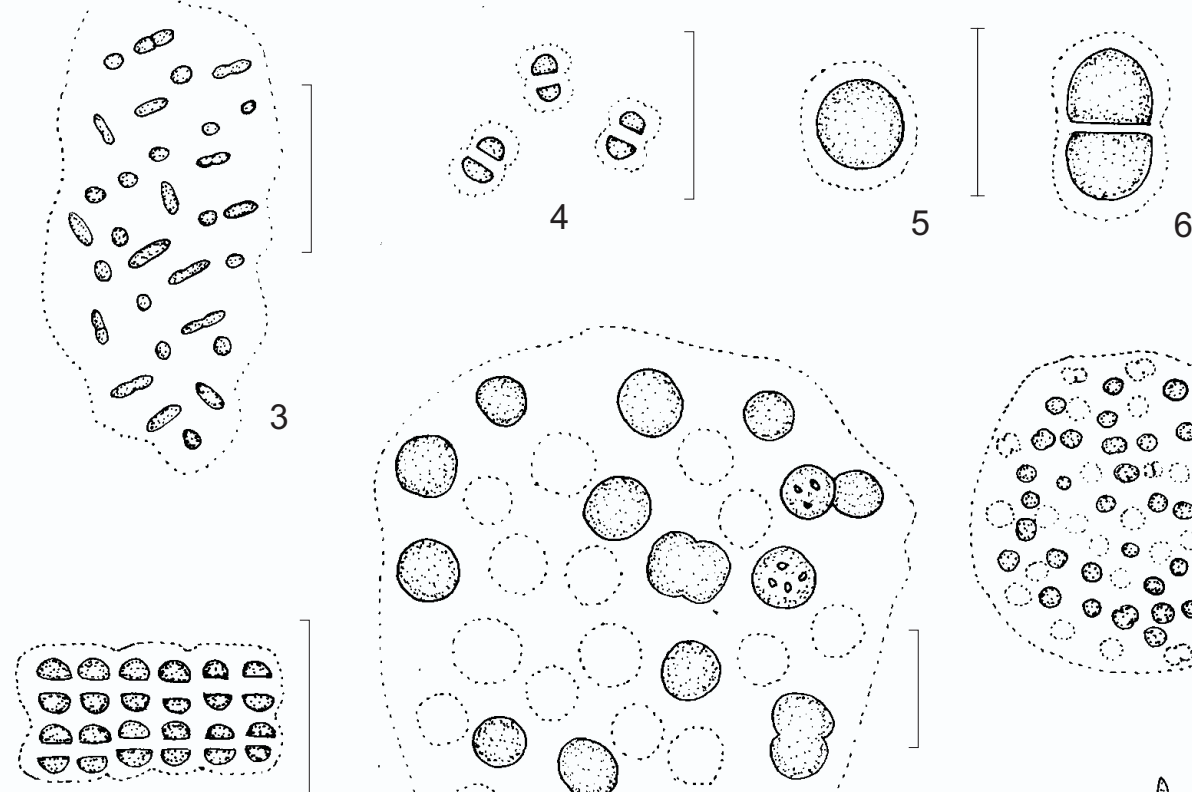

5

6
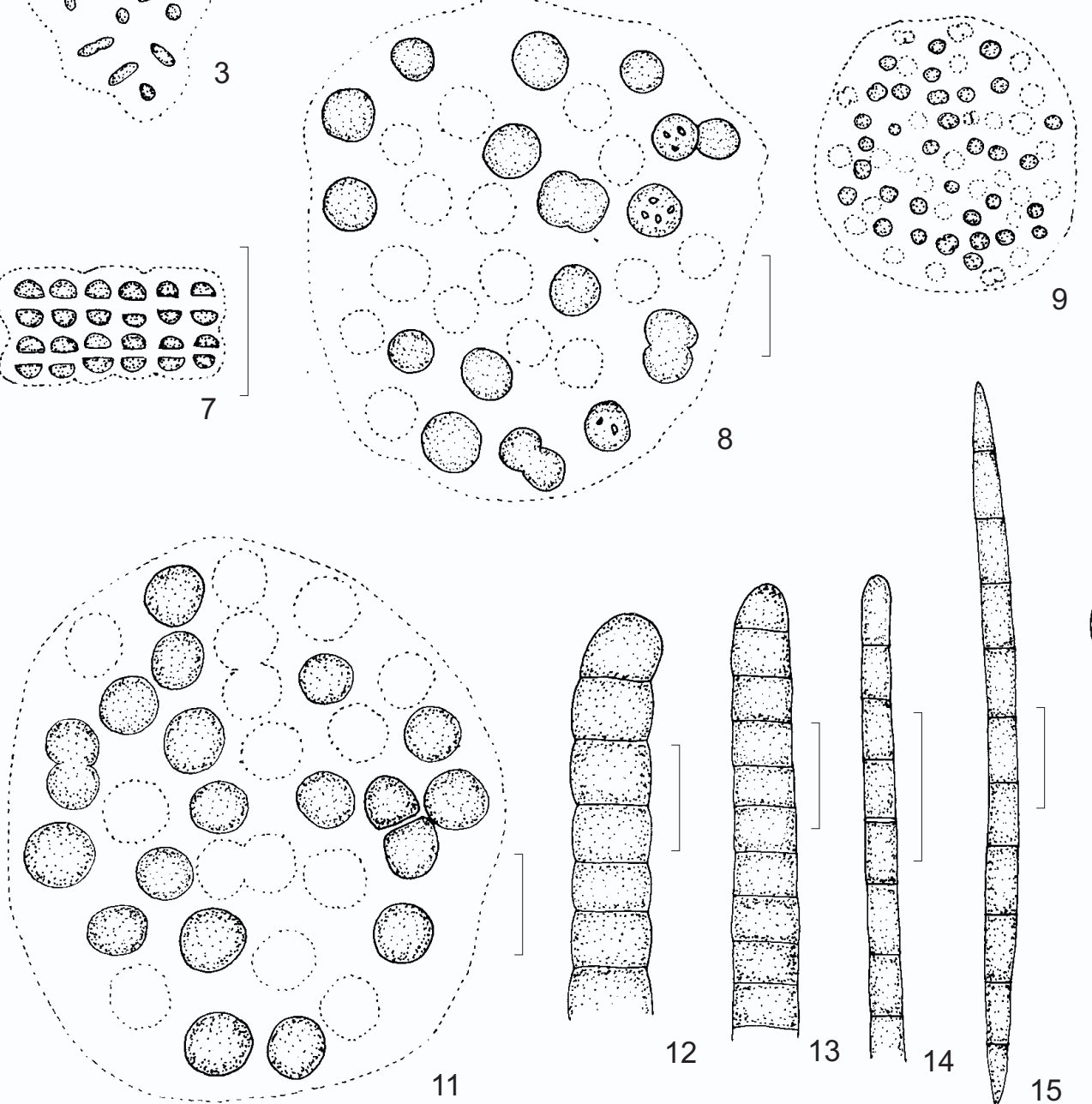

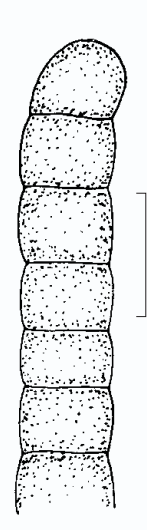

12

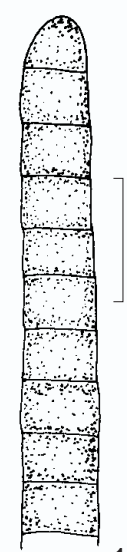

13

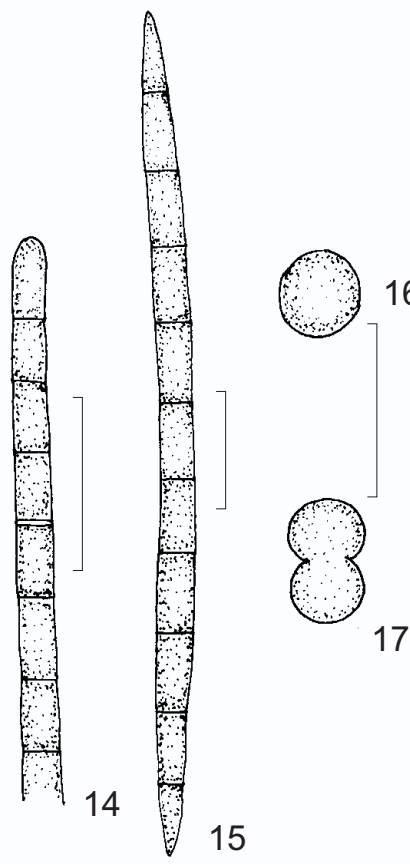

Fig. 3 - Aphanothece clathrata. Fig. 4 - Chroococcus minor. Figs. 5 e 6 - C. minutus. Fig. 7 - Merismopedia tenuissima. Fig. 8 - Microcystis aeruginosa f. flos-aquae. Fig. 9 - M. incerta. Fig. 10 - Lyngbya limnetica. Fig. 11 - Microcystis robusta. Fig. 12 - Oscillatoria boryana. Fig. 13 - O. simplicissima. Fig. 14 - O. subtilissima. Fig. 15 - Raphidiopsis mediterranea. Figs. 16 e $17-$ Synechocystis aquatilis. (Escalas $=10 \mu \mathrm{m}$. ) 


\section{Classe Chlorophyceae}

Actinastrum aciculare Playf. f. minimum (Hub.-Pest.) Comp. (Fig. 18)

Bull. Jard. Bot. Nat. Belg., 46: 228, 1976.

Cenóbios 4-12 células cônicas dispostas radialmente; cloroplasto único, parietal, 1 pirenóide. Compr. das células 8-12 $\mu \mathrm{m}$, larg. 0,5-1 $\mu \mathrm{m}$.

Ankistrodesmus bernardii Kom. (Fig. 19)

Nova Hedwigia 37: 138, pl. 25, Fig. 65, 1983.

Colônias 8-16 células fusiforme-alongadas; curvas na região mediana, atenuando gradualmente em direção aos ápices; cloroplasto único, parietal, sem pirenóide. Compr. das células 35-60 $\mu \mathrm{m}$, larg. 1-2 $\mu \mathrm{m}$.

Ankistrodesmus falcatus (Corda) Ralfs (Fig.

Brit. Desm., p. 180, pl. 34, Figs. a-c,1848.

Colônias com 1-2 fascículos de 4 células falciformes, dispostos cruciada ou irregularmente; células unidas entre si pela porção mediana convexa; cloroplasto único, parietal, sem pirenóide. Compr. das células 30-44 $\mu \mathrm{m}$, larg. 2-3 $\mu \mathrm{m}$.

Asterococcus limneticus G. M. Smith (Fig. 21)

Trans. Wis. Acad. Sci. Arts Lett., 19(1): 614, 1918.

Células isoladas, esféricas; mucilagem inconspícua; cloroplasto único, lobado radialmente, 1 pirenóide. Diâm. das células 12-16 $\mu \mathrm{m}$.

Chlamydomonas microscopica $\mathrm{G}$. S. West (Fig. 22)

J. Bot., 54: 1, 1916.

Células isoladas, ovadas; 2 flagelos iguais apicais; cloroplasto único, poculiforme, 1 pirenóide. Compr. das células $8-9,5 \mu \mathrm{m}$, larg. 3,5-4,5 $\mu \mathrm{m}$.

Chlorella homosphaera Skuja (Fig. 23)

Symb. bot. Upsal., 9(3): 130, pl. 15, Figs. 13a-k, 1948.

Células isoladas, esféricas; cloroplasto único, parietal, poculiforme, sem pirenóide. Diâm. das células 2-4 $\mu \mathrm{m}$.

Chlorolobion braunii (Nag.) Kom. (Figs. 2425)

Algol. Stud., 24: 255, 1979.

Células isoladas, fusiforme-alongadas, pólos afilados; cloroplasto único, parietal, lateral, 1 pirenóide. Compr. das células adultas $16-22 \mu \mathrm{m}$, larg. 2,5-5,5 $\mu \mathrm{m}$; compr. dos autósporos $12-14 \mu \mathrm{m}$, larg. $1,5-2,5 \mu \mathrm{m}$.

Choricystis cylindracea Hind. (Figs. 26-27)
Biol. Prace, 34(1/2): 182, pl. 65, Figs. 1-2, 1988.

Células isoladas, cilíndricas a ovadas; cloroplasto único, parietal, sem pirenóide. Compr das células 3-5 $\mu \mathrm{m}$, larg. 1,5-2 $\mu \mathrm{m}$.

Coelastrum reticulatum (Dang.) Senn (Fig. 28)

Bot. Ztg., 57: 66, pl. 2, Figs. 1-10, 1899.

Cenóbios esféricos 4-8-16 células esféricas, 5-6 processos de união, cada um unindo-se a uma célula vizinha; cloroplasto único, parietal, 1 pirenóide; sincenóbios freqüentes. Diâm. das células 8-11 $\mu \mathrm{m}$.

Coelastrum sphaericum Näg. (Fig. 29)

Gatt. einzell. Algen, 97, pl. 5c, Figs. 1a-d, 1849.

Cenóbios quadráticos ou cúbicos, 4-8 células justapostas entre si, sem processos de união; células cônico-truncadas com a base voltada para o centro do cenóbio, paredes laterais geralmente côncavas; cloroplasto único, parietal, 1 pirenóide. Compr. das células 3,5-5 $\mu \mathrm{m}$, larg. 5-7 $\mu \mathrm{m}$.

Crucigenia tetrapedia (Kirch.) West \& West (Fig. 30)

Trans. R. Ir. Acad., 32: 62, Sér. B, pl. 1, Figs. 11-12, 1902.

Cenóbios planos, quadrangulares, 2-4 células triangulares dispostas cruciadamente, espaço central ausente; cloroplasto único, parietal, sem pirenóide. Compr. das células 2,5-4 $\mu \mathrm{m}$, larg. 4$5,5 \mu \mathrm{m}$.

Crucigeniella pulchra (West \& West) Kom. (Fig. 33)

Arch. Protistenk., 116: 39, Fig. 14, 1974.

Cenóbios planos, alongados, 4 células reniformes dispostas cruciadamente, margem externa côncava, pólos com 1 papila; espaço intercelular rômbico; cloroplasto único, parietal, 1 pirenóide. Compr. das células 5-6 $\mu \mathrm{m}$, larg. 2,5-3,5 $\mu \mathrm{m}$.

Dictyosphaerium pulchellum Wood (Fig. 3132)

Smithson. Contr. Knowl. 19(241): 84, pl. 10, Fig. 4, 1872.

Colônias arredondadas, grupos de 4-8 células esféricas unidas por pedúnculos mucilaginosos; cloroplasto único, poculiforme, 1 pirenóide. Diâm. das células adultas $4-5 \mu \mathrm{m}$; diâm. dos autósporos 2-3 $\mu \mathrm{m}$.

Elakatothrix gelifacta (Chod.) Hind. (Fig. 34) 
Preslia 59: 207, Figs. 6-11, 1987.

Células isoladas, fusiformes, geralmente constrictas na porção mediana; cloroplasto único, parietal, 2 pirenóides. Compr. das células 15$22 \mu \mathrm{m}$, larg. 1,5-3 $\mu \mathrm{m}$.

Eudorina elegans Ehrenb. (Fig. 35)

Abh. dt. Akad. Wiss. Berl., 1831: 78, pl. 2, Figs. 10a-b, 1832.

Colônias arredondadas, 24-32 células esféricas, dispostas em 5 séries paralelas distintas de 4-8-8-8-4; cloroplasto único, poculiforme, 1 pirenóide, 2 flagelos iguais. Diâm. das células 5$6,5 \mu \mathrm{m}$.

Eutetramorus planctonicus (Kors.) Bourr. (Fig. 36) 2, 1966

Int. Revue ges. Hydrobiol. Hydrogr. 51(1):

Colônias arredondadas, 4-8 células esféricas dispostas 2 a 2 em planos diferentes; cloroplasto único, poculiforme, 1 pirenóide. Diâm. das células $5-7 \mu \mathrm{m}$.

Franceia javanica (Bern.) Hortob. (Fig. 37)

Nova Hedwigia, 4(1/2): 28, pl. 43, Figs. 527529, 1962.

Células isoladas, elípticas; cloroplasto único, parietal, 1 pirenóide; parede celular com 16-20 setas. Compr. das células 9-12 $\mu \mathrm{m}$, larg. 4,5-5,5 $\mu \mathrm{m}$; compr. das setas 5-8 $\mu \mathrm{m}$.

Golenkinia paucispina West \& West (Fig. 38) 1902.

Trans. R. Ir. Acad., 32: 68, pl. 1, Fig. 18,

Células isoladas, esféricas, numerosos espinhos retos dispostos regularmente; cloroplasto único, parietal, poculiforme, 1 pirenóide reniforme basal. Diâm. das células 9-11 $\mu \mathrm{m}$; compr. dos espinhos $8-13 \mu \mathrm{m}$.

Keratococcus sueciccus Hind. (Figs. 39-40)

Biol. Prace, 23(4): 119, 1977.

Células isoladas, alongadas, retas ou curvas, ápices afilados, semelhantes a pêlos, às vezes também curvos; cloroplasto único, parietal, 1 a 2 pirenóides. Compr. das células 25-45 $\mu \mathrm{m}$, larg. 3-4 $\mu \mathrm{m}$.

Kirchneriella microscopica Nyg. (Fig. 41)

Dansk Plante-Plankton, 1945.

Colônias com 4-8 células lunadas, ápices arredondados; cloroplasto único, parietal, sem pirenóide. Distância entre os ápices das células 1-1,5 $\mu \mathrm{m}$, larg. 2-3 $\mu \mathrm{m}$, diâm. 0,5-1 $\mu \mathrm{m}$.

Kirchneriella roselata Hind. (Fig. 42)
Biol. Prace, 30: 232, pl. 84, 1984.

Colônias alongadas, 2-4 células lunadas, ápices acuminados, lado côncavo orientado para o centro da colônia, restos mucilaginosos presentes; cloroplasto único, parietal, sem pirenóide. Distância entre os ápices das células 2,5-3,5 $\mu \mathrm{m}$, larg.

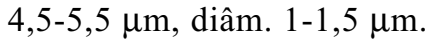

Koliella longiseta (Visch.) Hind. f. tenuis Nyg. (Fig. 43)

K. danske Vidensk. Selsk. Skr., 21(1): 72, Fig. 65, 1977.

Células isoladas, fusiforme-alongadas, retas, ápices acuminados semelhantes a pêlos; cloroplasto único, parietal, sem pirenóide. Compr. das células $45-50 \mu \mathrm{m}$, larg. 0,5-1 $\mu \mathrm{m}$.

Lagerheimia tetraedriensis Roll (Fig. 44) Arch. Russ. Protistol., 6: 225-231, 1927.

Células isoladas, tetraédricas, lados convexos, 4 espinhos retos, um em cada pólo; cloroplasto único, 1 pirenóide. Diâm. das células $c a .4 \mu \mathrm{m}$; compr. dos espinhos $c a .8 \mu \mathrm{m}$.

Monoraphidium contortum (Thur.) Kom.Legn. (Fig. 45)

Stud. Phycol., p. 104, pl. 18, Figs. 1-5. 1969.

Células isoladas, fusiforme-alongadas, helicoidais, com 1-1,5 voltas, ápices gradualmente afilados; cloroplasto único, parietal, sem pirenóide. Distância entre os ápices das células 10-16 $\mu \mathrm{m}$, diâm. 1-1,5 $\mu \mathrm{m}$, larg. 3,5-5 $\mu \mathrm{m}$.

Monoraphidium convolutum (Corda) Kom.Legn. (Fig. 46)

Stud. Phycol., p. 107, pl. 19, 1969.

Células isoladas, lunadas, ápices dispostos em planos diferentes; cloroplasto único, parietal, sem pirenóide. Distância entre os ápices das células 6-9 $\mu \mathrm{m}$, larg. 4,5-7 $\mu \mathrm{m}$, diâm. 1,5-3 $\mu \mathrm{m}$.

Monoraphidium irregulare (G. M. Smith) Kom.-Legn. (Fig. 47)

Stud. Phycol., p. 106, pl. 19, 1969.

Células isoladas, fusiforme-alongadas, helicoidais, com 2 voltas; cloroplasto único, parietal, sem pirenóide. Distância entre os ápices das células 20-31 $\mu \mathrm{m}$, diâm. 1-2 $\mu \mathrm{m}$, larg. 5-8 $\mu \mathrm{m}$.

Monoraphidium komarkovae Nyg. (Fig. 48)

Bot. Tidsskr., 73(3/4): 212, 1979.

Células isoladas, fusiforme-alongadas, retas, ápices gradualmente afilados, às vezes curvos, terminando em forma de pêlo; cloroplasto único, parietal, sem pirenóide. Compr. das células 40-55 $\mu \mathrm{m}$, diâm. 1,5-2,5 $\mu \mathrm{m}$. 

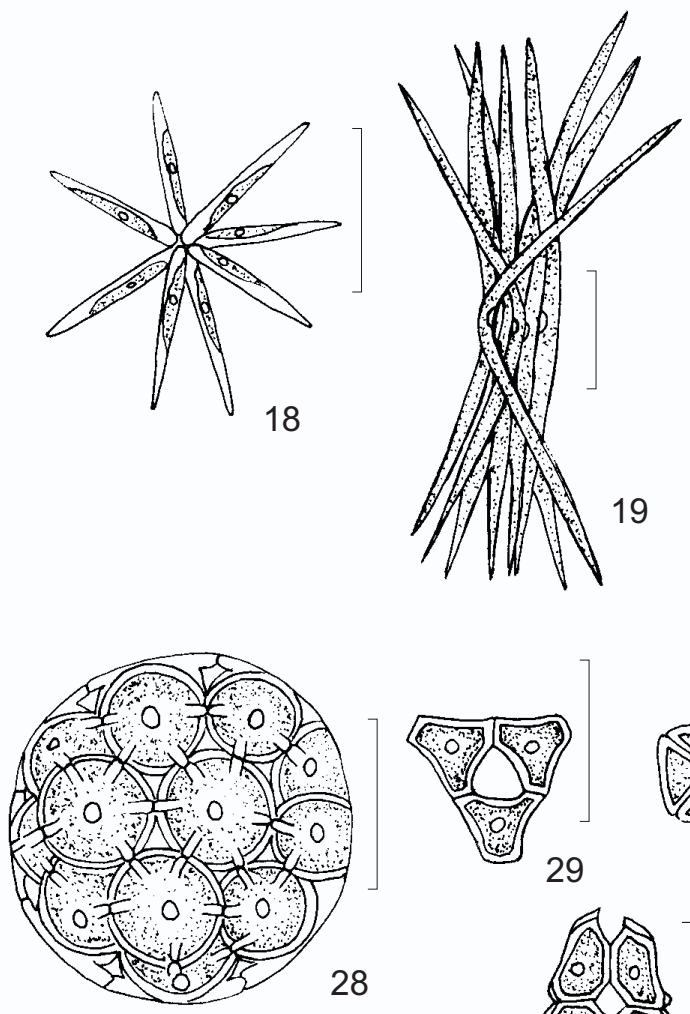

29
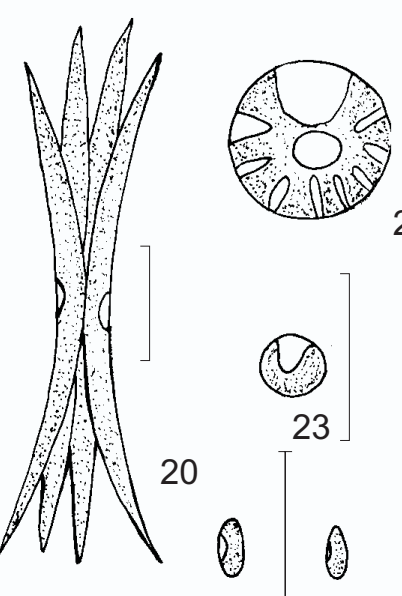

21

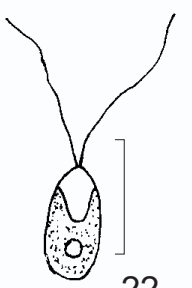

22

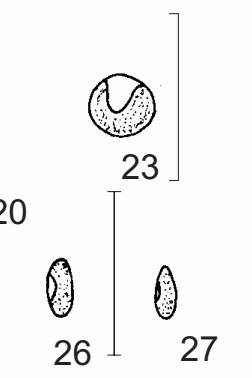

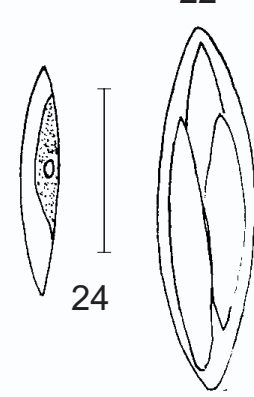
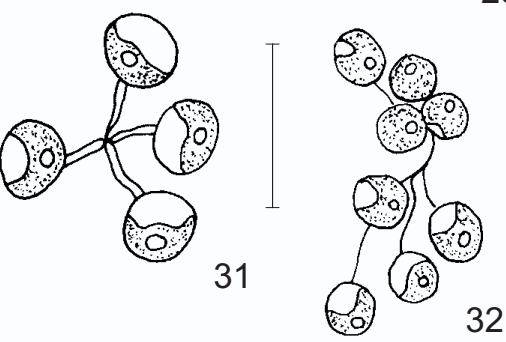

33
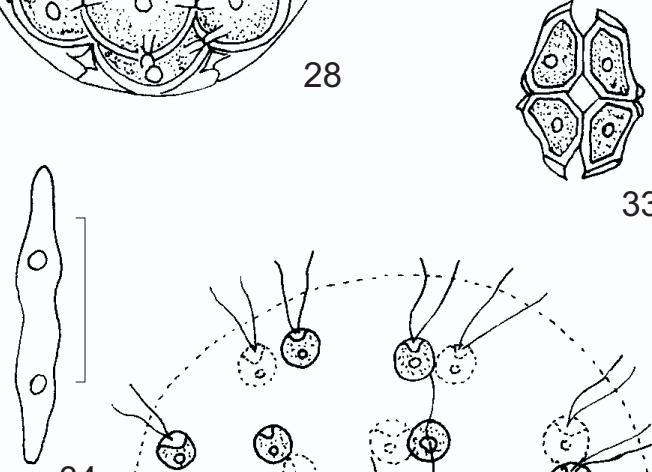

30

31

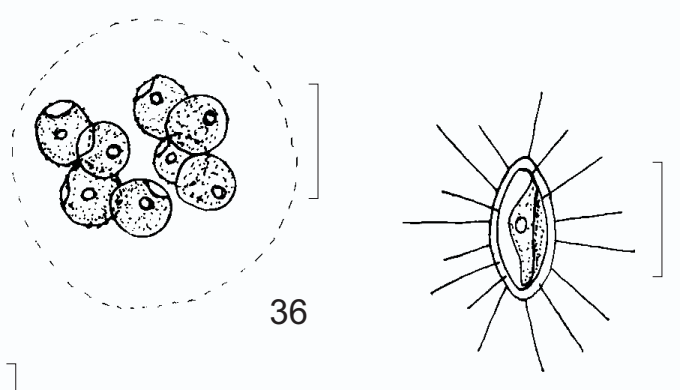
34<smiles>C1=CCCCC1</smiles>
of 6 ?

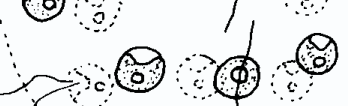<smiles>C1=CC=C1</smiles><smiles>C#CC=CC(=O)C#C</smiles>

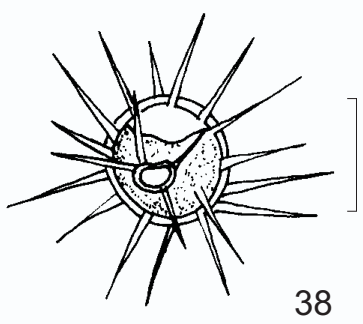

Fig. 18 - Actinastrum aciculare f. minimum. Fig. 19 - Ankistrodesmus bernardii. Fig. 20 - A. falcatus. Fig. 21 - Asterococcus limneticus. Fig. 22 - Chlamydomonas microscopica. Fig. 23 - Chlorella homosphaera. Figs. 24 e 25 - Chlorolobium braunii. Figs. 26 e 27 - Choricystis cylindracea. Fig. 28 - Coelastrum reticulatum. Fig. 29 - C. sphaericum. Fig. 30 Crucigenia tetrapedia. Figs. 31 e 32 - Dictyosphaerium pulchellum. Fig. 33 - Crucigeniella pulchra. Fig. 34 - Elakatothrix gelifacta. Fig. 35 - Eudorina elegans. Fig. 36 - Eutetramorus planctonicus. Fig. 37 - Franceia javanica. Fig. 38 Golenkinia paucispina. (Escalas $=10 \mu \mathrm{m}$.) 

49)

Monoraphidium longiusculum Hind. (Fig.

Biol. Prace 30: 222, pl. 80, Figs. 2-4, 1984.

Células isoladas, fusiforme-alongadas, sigmóides; cloroplasto único, parietal, sem pirenóide; incisão nuclear mediana ampla. Distância entre os ápices das células 45-60 $\mu \mathrm{m}$, diâm. 1,5-3 $\mu \mathrm{m}$.

Monoraphidium minutum (Näg.) Kom.-Legn. (Fig. 50)

Stud. Phycol., p. 109, pl. 22, Figs. 1-4, 1969.

Células isoladas, lunadas, ápices arredondados, dispostos no mesmo plano; cloroplasto único, parietal, sem pirenóide. Distância entre os ápices das células 3-4,5 $\mu \mathrm{m}$, larg. 6,5-8 $\mu \mathrm{m}$, diâm. 2-4 $\mu \mathrm{m}$.

Monoraphidium nanum (Ettl) Hind. (Fig. 51)

Biol. Prace 26(6): 145, pl. 59, Figs. 2-4, 1980.

Células isoladas, lunadas, ápices arredondados, dispostos no mesmo plano; cloroplasto único, parietal, sem pirenóide. Distância entre os ápices das células 2,5-3 $\mu \mathrm{m}$, larg. 3-4 $\mu \mathrm{m}$, diâm. 1-1,5 $\mu \mathrm{m}$.

Nephrochlamys subsolitaria (G. S. West) Kors. (Fig. 52)

Protococcineae, p. 311, Fig. 278, 1953.

Colônias lunadas; 2 -4 células lunadas, ápices arredondados; cloroplasto único, poculiforme, sem pirenóide. Larg. das células adultas 6-7 $\mu \mathrm{m}$, diâm. 4-5 $\mu \mathrm{m}$; larg. dos autósporos 4-5 $\mu \mathrm{m}$, diâm. 1,5$3 \mu \mathrm{m}$.

Oocystis lacustris Chod. (Figs. 53-54)

Bull. Herb. Boissier, 5: 119, pl. 10, Figs. 17, 1897.

Colônias elípticas ou arredondadas, geralmente com espessamento; 2-4-8 células elípticas, geralmente sem espessamento, dispostas irregularmente em mucilagem hialina, conspícua, raramente isoladas; 2 cloroplastos parietais em forma de escudo, 1 pirenóide. Compr. das células adultas 9-14 $\mu \mathrm{m}$, larg. 6-10 $\mu \mathrm{m}$; compr. dos autósporos 4,5-8 $\mu \mathrm{m}$, larg. 2-3,5 $\mu \mathrm{m}$.

Pediastrum duplex Meyen (Fig. 56)

Nova acta Acad. Caesar. Leop. Carol. 14: 772, pl. 43, Figs. 6-20, 1829.

Cenóbios arredondados, 16-32 células dispostas concentricamente, espaços intercelulares presentes; células poligonais, as externas unidas entre si pela base e com 2 processos cilíndricotruncados; cloroplasto único, parietal, ocupando toda a célula, 1 pirenóide. Diâm. dos cenóbios 50$90 \mu \mathrm{m}$; compr. das células externas 18-22 $\mu \mathrm{m}$, larg. 13-16 $\mu \mathrm{m}$; compr. das células internas $13-17 \mu \mathrm{m}$, larg. $10-16 \mu \mathrm{m}$.

Pediastrum privum (Printz) Hegew. (Fig. 55) 25, 1979.

In: Hegewald \& Schnepf, Algol. Stud., 22:

Cenóbios quadráticos; 4 células triangulares dispostas cruciadamente, margem externa com 2 projeções em cada ângulo; cloroplasto parietal ocupando toda a célula, 1 pirenóide. Diâm. dos cenóbios 7,5-10 $\mu \mathrm{m}$; compr. das células 4,5-5,5 $\mu \mathrm{m}$, larg. 6,5-9 $\mu \mathrm{m}$.

Pediastrum tetras (Ehrenb.) Ralfs (Fig. 57) Ann. Mag. nat. Hist., 14: 469, pl. 2, Fig. 4, 1844.

Cenóbios quadráticos ou arredondados; 48 células dispostas concentricamente, espaços intercelulares ausentes, células externas e internas poligonais, as externas com 2 processos bifurcados; cloroplasto único, parietal, ocupando toda a célula, 1 pirenóide. Diâm. dos cenóbios 20-28 $\mu \mathrm{m}$; compr. das células externas $8-10 \mu \mathrm{m}$, larg. 6-10 $\mu \mathrm{m}$; compr. das células internas 6-7 $\mu \mathrm{m}$, larg. 5-7 $\mu \mathrm{m}$.

Quadrigula pfitzeri (Schröd.) G. M. Smith (Fig. 58)

Bull. Wis. geol. nat. Hist. Surv., 57: 243, 1920.

Colônias 2-4 células dispostas em feixes, paralelamente a seus eixos longitudinais; células fusiformes; cloroplasto único, parietal, sem pirenóide. Compr. das células 12-16 $\mu \mathrm{m}$, larg. 1,5$3 \mu \mathrm{m}$.

Scenedesmus acuminatus (Lagerh.) R. Chod. (Fig. 59)

Beitr. KryptogFlora Schweiz., 1(3): 211, 1902.

Cenóbios retos a levemente curvos, 2-4-8 células lunadas dispostas linearmente; cloroplasto único, parietal, 1 pirenóide. Compr. das células 9-12 $\mu \mathrm{m}$, larg. 1-2 $\mu \mathrm{m}$.

Scenedesmus arcuatus (Lemm.) Lemm. var. platydiscus G. M. Smith (Fig. 60)

Trans. Wis. Acad. Sci. Arts Lett., 18: 451, pl. 30, Figs. 101-105, 1916.

Cenóbios curvos com 2 fileiras de 4-8 células oblongas dispostas linearmente; cloroplasto único, parietal, 1 pirenóide. Compr. das células 5-6 $\mu \mathrm{m}$, larg 2,5-3 $\mu \mathrm{m}$. 


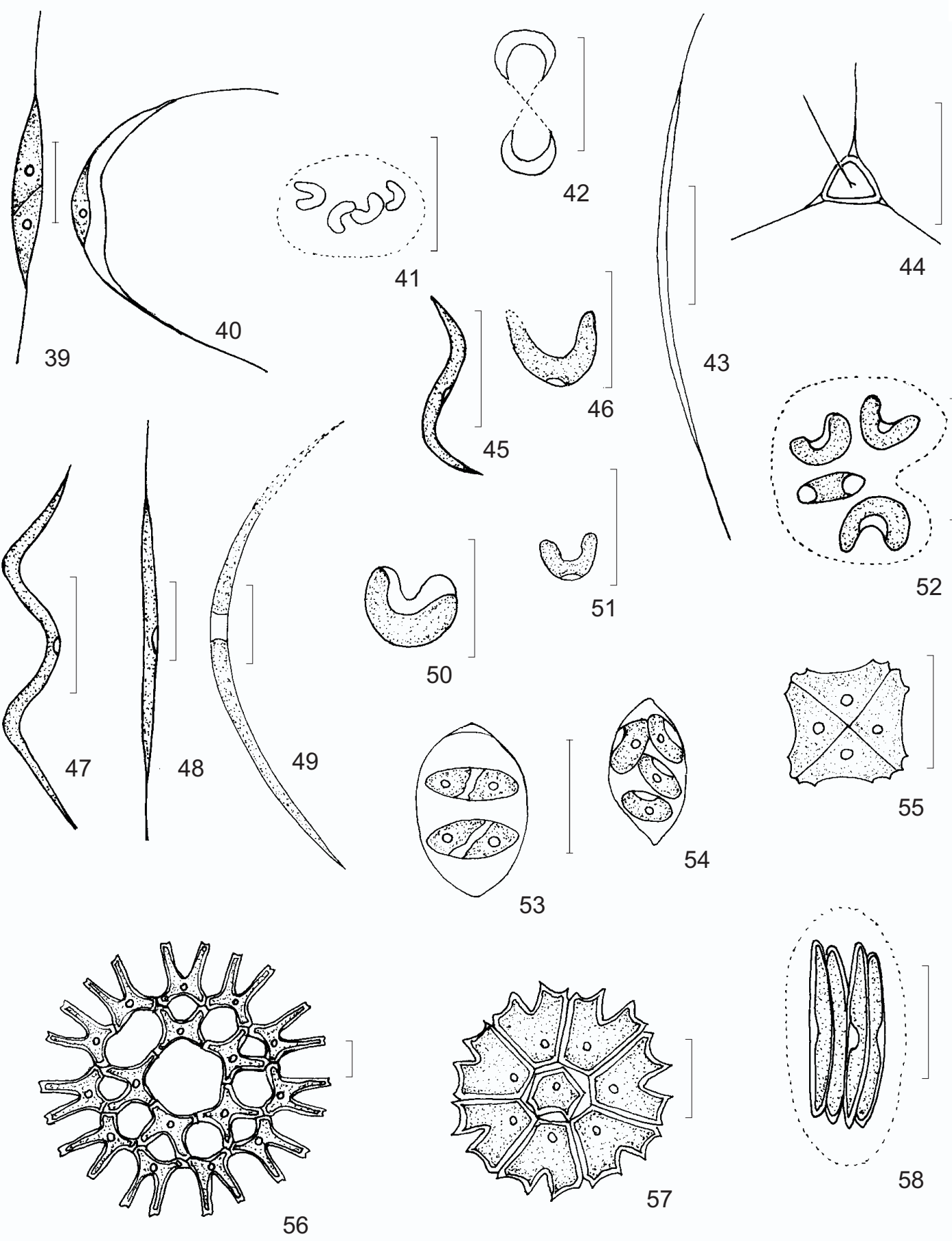

Figs. 39 e 40 - Keratococcus sueciccus. Fig. 41 - Kirchneriella microscopica. Fig. 42 - K. rosellata. Fig. 43 - Koliella longiseta f. tenuis. Fig. 44 - Lagerheimia tetraedriensis. Fig. 45 - Monoraphidium contortum. Fig. 46 - M. convolutum. Fig. $47-M$. irregulare. Fig. $48-M$. komarkovae. Fig. $49-M$. longiusculum. Fig. $50-M$. minutum. Fig. $51-M$. nanum. Fig. 52 - Nephrochlamys subsolitaria. Figs. 53 e 54 - Oocystis lacustris. Fig. 55 - Pediastrum privum. Fig. $56-$ P. duplex. Fig. $57-$ P. tetras. Fig. $58-$ Quadrigula pfitzeri. $($ Escalas $=10 \mu \mathrm{m}$.) 
Scenedesmus denticulatus Lagerh. (Fig. 61)

Öfvers. K. VetenskAkad. Forh., 39(2): 61, pl. 2, Fig. 13-16, 1882.

Cenóbios retos, 4 células ovadas a subovadas dispostas alternadamente, 2 espinhos curtos em cada pólo; cloroplasto único, parietal, 1 pirenóide. Compr. das células 8-12 $\mu \mathrm{m}$; larg. 4-6,5 $\mu \mathrm{m}$; compr. dos espinhos 1-1,5 $\mu \mathrm{m}$.

Scenedesmus ellipticus Corda (Fig. 62)

Alm. Carlsbad, 5: 208, pl. 4, Fig. 48-49, 1835.

Cenóbios retos, 2-4 células oblongas dispostas linearmente; cloroplasto único, parietal, 1 pirenóide. Compr. das células 5-7 $\mu \mathrm{m}$, larg. 1,5-2,5 $\mu \mathrm{m}$.

Scenedesmus javanensis R. Chod. (Fig. 63)

Z. Hydrol. 3: 157, Fig. 47, 1926.

Cenóbios retos, 4-8 células lunadas dispostas em ziguezague, um dos pólos de cada célula interna unido à região mediana convexa da célula vizinha, exceto nas células centrais; cloroplasto único, parietal, 1 pirenóide. Compr. das células 24-30 $\mu \mathrm{m}$, larg. 2-3,5 $\mu \mathrm{m}$.

Scenedesmus longispina R. Chod. (Fig. 64)

Monogr. Alg. Cult. Pure, p. 60, Figs. 53-57, pl. 2, Figs. 9 e 10, 1913.

Cenóbios retos, 2-4 células oblongas dispostas linearmente, as externas com 1 espinho e um dente em cada pólo, as internas com 1 dente em cada pólo; cloroplasto único, parietal, 1 pirenóide. Compr. das células 6-10 $\mu \mathrm{m}$, larg. 2,5-3,5 $\mu \mathrm{m}$; compr. dos espinhos das células externas $6-8 \mu \mathrm{m}$, dos dentes 1-1,5 $\mu \mathrm{m}$.

Scenedesmus opoliensis P. Rich. var. danubialis Hortob. (Fig. 65)

Biol. Közlem., 19: 25, Fig. 4, 1971.

Cenóbios retos, 4-8 células oblongas dispostas linearmente, as externas com pólos truncados, voltados para fora, cada um com 1 espinho, as internas com um dos pólos arredondados, sem espinho, o outro cônico-truncado, com 1 espinho; espinhos das células internas dispostos diagonalmente em cada metade do cenóbio; cloroplasto único, parietal, 1 pirenóide. Compr. das células 15-25 $\mu \mathrm{m}$, larg. 5-9 $\mu \mathrm{m}$; compr. dos espinhos das células externas 10-20 $\mu \mathrm{m}$, das internas 8-15 $\mu \mathrm{m}$.

Scenedesmus protuberans Frits. \& Rich (Fig. 66)

Trans. R. Soc. S. Afr., 18: 31, Fig. 6, 1929.

Cenóbios retos, 2-4-8 células oblongas dispostas linearmente, as externas com pólos cônicoarredondados, curvos para fora com 1 espinho, margem externa convexa; cloroplasto único, parietal, 1 pirenóide. Compr. das células $15-20 \mu \mathrm{m}$, larg. 4,5-6,5 $\mu \mathrm{m}$; compr. dos espinhos 15-18 $\mu \mathrm{m}$. Scenedesmus spinosus R. Chod. (Fig. 67) Monogr. Alg. Cult. Pure, p. 74, pl. 2, Fig. 7, 1913.

Cenóbios retos, 2-4 células oblongas dispostas linearmente, as externas com 1 espinho longo em cada pólo, 1-2 espinhos curtos na região mediana da margem lateral, as internas com ou sem espinhos nos pólos; cloroplasto único, parietal, 1 pirenóide. Compr. das células 5-7 $\mu \mathrm{m}$, larg. 1,5$3 \mu \mathrm{m}$; compr. dos espinhos das células externas 3-4 $\mu \mathrm{m}$, das internas $1,5-2 \mu \mathrm{m}$.

Tetraedron caudatum (Corda) Hansg. (Fig. 68)

Hedwigia 27: 131, 1888.

Células isoladas, 5-anguladas, com um dos ângulos em planos diferentes; ângulos arredondados com 1 processo, margem côncava mais pronunciada entre dois dos ângulos; parede celular lisa; cloroplasto único, parietal, 1 pirenóide. Larg. das células 8-10 $\mu \mathrm{m}$; compr. dos processos 2,5$3 \mu \mathrm{m}$.

Tetraedron incus (Teil.) G. M. Smith. (Fig. 69-70)

Trans. Am. microsc. Soc., 45: 174, 1926.

Células isoladas, 4-anguladas; ângulos arredondados com 1 processo; margens côncavas; parede celular lisa; cloroplasto único, parietal, 1 pirenóide. Larg. das células 5-10 $\mu \mathrm{m}$; compr. dos processos 1,5-2,5 $\mu \mathrm{m}$.

Tetraedron minimum (A. Braun) Hansg. (Fig. 71)

Hedwigia 27: 131, 1888.

Células isoladas, 4-anguladas, um dos ângulos em plano diferente, ângulos arredondados com 1 papila, margens côncavas; parede celular lisa; cloroplasto único, parietal, 1 pirenóide. Larg. das células 4,5-6 $\mu \mathrm{m}$.

Tetrallantos lagerheimii Teil. (Fig. 72)

Svensk bot. Tidskr. 10: 62, 1916.

Cenóbios de 4-8 células lunadas, ápices arredondados, duas delas dispostas no mesmo plano unidas em ambos os pólos, formando um anel, cada região de união ligando-se ao pólo de outra célula perpendicular ao anel; mucilagem hialina; cloroplasto único, parietal, 1 pirenóide. Compr. dos cenóbios 39-45 $\mu \mathrm{m}$; larg. das células $2-3 \mu \mathrm{m}$, distância entre os ápices 5,5-7 $\mu \mathrm{m}$. 
Tetrastrum heteracanthum (Nordst.) R. Chod. (Fig. 73)

Bull. Herb. Boissier, 3: 113, 1895.

Cenóbios planos, quadrangulares, 4 células dispostas cruciadamente, espaço intercelular retangular; células subtriangulares, margem externa reta, com 2 espinhos retos de diferentes tamanhos; cloroplasto único, parietal, 1 pirenóide. Compr. das células 3,5-4,5 $\mu \mathrm{m}$; larg. 4,5-6,5 $\mu \mathrm{m}$; compr. dos espinhos longos 6-7,5 $\mu \mathrm{m}$, dos de tamanho intermediário $1-2,5 \mu \mathrm{m}$.

\section{Classe Zygnemaphyceae}

Actinotaenium perminutum (G. S. West) Teil. (Figs. 74-75)

Folia geobot. Phytotax., 13: 56, 1978.

Células 1,4-1,6 vez mais longas que largas, oblongas; constricção mediana rasa; cloroplasto axial, estrelado, 1 pirenóide. Compr. das células 9,5-12 $\mu \mathrm{m}$, larg. 6-7,5 $\mu \mathrm{m}$, istmo 5-6,5 $\mu \mathrm{m}$.

Cosmarium bioculatum (Bréb.) ex Ralfs var. depressum (Sch.) Schm (Figs. 76-77)

Chloroph. Fl. Flora, 78(1): 51, 1894.

Células tão largas quanto longas; seno fechado; semicélulas oblongas; vista vertical oblonga; parede celular lisa; cloroplasto axial, 1 pirenóide. Compr. das células 10-12 $\mu \mathrm{m}$, larg. 8-11 $\mu \mathrm{m}$, istmo 2,5-3 $\mu \mathrm{m}$

Cosmarium contractum Kirch. var. minutum (Delp.) West \& West. (Figs.78-79)

Mon. brit. Desm. v. 2, p. 173, pl. 61, Figs. 30-33, 1905.

Células 1,3-1,6 vez mais longas que largas; seno aberto; semicélulas subcirculares; vista vertical oblonga; parede celular lisa; cloroplasto axial, 1 pirenóide. Compr. das células 16-20 $\mu \mathrm{m}$, larg. $10,5-14,5 \mu \mathrm{m}$, istmo $5-8 \mu \mathrm{m}$.

Cosmarium sphagnicolum West \& West var. apertum (Skuja) Först. (Figs. 80-81)

Algol. Stud., 28: 242, 1981.

Células tão longas quanto largas; seno aberto; semicélulas trapeziformes, ângulos superiores com 1 papila, ápices retusos; vista vertical oblonga, lados côncavos; cloroplasto axial, 1 pirenóide. Compr. das células 7-8,5 $\mu \mathrm{m}$, larg. 7-8,5 $\mu \mathrm{m}$, istmo 2-3,5 $\mu \mathrm{m}$.

Euastrum binale (Turp.) Ehrenb. var. hians (W. West) Krieg. (Fig. 82)
Rabenhorst's KryptogamenFlora Deutschl, 13(1-3):551, pl. 75, Fig. 16, 1937.

Células 1,4-1,5 vez mais longas que largas; seno fechado; semicélulas trapezoidais, lobos basais sub-retangulares, obliquamente truncados, margens laterais divergentes a partir do seno mediano até a metade da semicélula, posteriormente retusas, convergentes até a base do lobo polar; ângulos apicais afilados formando apículos; parede celular lisa; cloroplasto, axial, 1 pirenóide. Compr. das células 12-16 $\mu \mathrm{m}$, larg. 9,5-11 $\mu \mathrm{m}$, istmo 2-3 $\mu \mathrm{m}$.

Staurastrum affine W. West \& G. West. (Figs. 83-84)

Trans. Bot. Soc. Edinburgh, 23: 26, pl. 2, Fig. 27, 1905.

Células 1,3-1,6 vez mais largas que longas; seno aberto; semicélulas piramidais truncadas, margens lateral e apical levemente convexas, ângulos prolongados em processos com 2 círculos de denticulações, terminados em 3 espinhos; vista vertical triangular, lados levemente côncavos; parede celular com séries concêntricas de grânulos. Compr. das células 18-23 $\mu \mathrm{m}$, larg.28-32 $\mu \mathrm{m}$ (c/ proc.), istmo 8-9 $\mu \mathrm{m}$.

Staurastrum muticum (Bréb.) ex Ralfs. (Figs. 85-86)

Brit. Desm. p. 125, pl. 21, Fig. 4, pl. 24, Fig. 13,1848

Células 1,2-1,3 vez mais longas que largas; seno aberto; semicélulas piramidais truncadas, ângulos arredondados; vista vertical triangular, lados côncavos; parede celular lisa. Compr. das células 18-21 $\mu \mathrm{m}$, larg. 13-16 $\mu \mathrm{m}$, istmo 5-8 $\mu \mathrm{m}$.

Staurastrum quadrangulare Bréb. var. contectum (Turn.) Gröenbl. (Figs. 87-88)

Acta Soc. Sci. Fenn., 2(6): 29, pl. 12, Fig. 255, 1945.

Células 1,1-1,2 vez mais largas que longas; seno aberto; semicélulas piramidais truncadas, margens laterais terminando em ângulos bifurcados, cada um com um par de espinhos robustos divergentes; vista vertical 5-angular, margens côncavas, ângulos arredondados, bifurcados, cada um com 1 par de espinhos robustos divergentes. Compr. das células $22-25 \mu \mathrm{m}$, larg. 26-29 $\mu \mathrm{m}$ (c/ proc.), istmo 10,5$12 \mu \mathrm{m}$.

Staurastrum quadrinotatum Grönbl. (Figs. 89-90) 
Fig. 59 - Scenedesmus acuminatus. Fig. $60-$ S. arcuatus var. platydiscus. Fig. $61-$ S. denticulatus. Fig. $62-$ S. ellipticus. Fig. $63-S$. javanensis. Fig. $64-$ S. longispina. Fig. $65-S$. opoliensis var. danubialis. Fig. $66-S$. protuberans. Fig. $67-$ S. spinosus. Fig. 68 - Tetraedron caudatum. Fig. 69 e $70-$ T. incus. Fig. $71-$ T. minimum. Fig. $72-$ Tetrallantos lagerheimii. Fig. $\mathbf{7 3}$ - Tetrastrum heteracanthum. (Escalas $=10 \mu \mathrm{m}$.) 

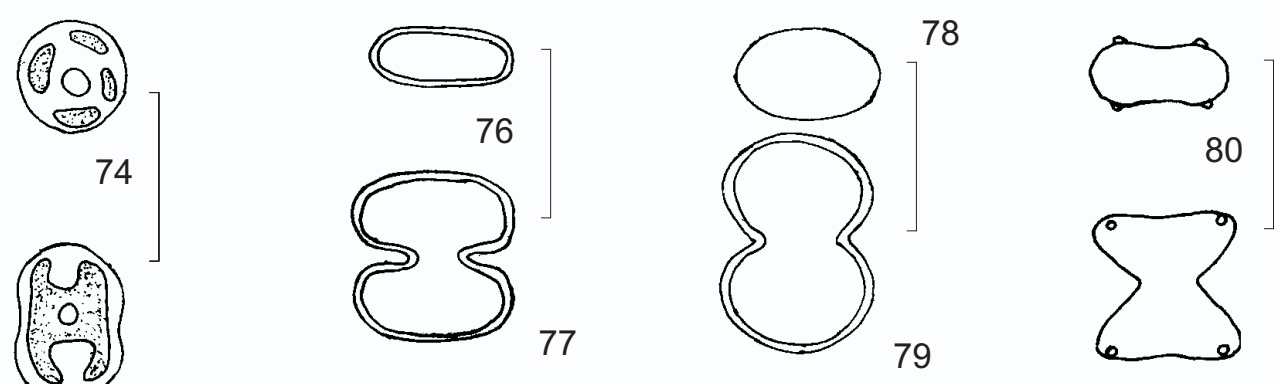

75
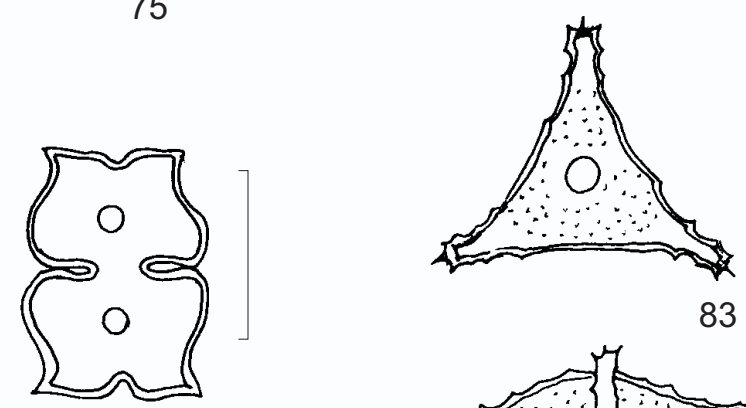

83
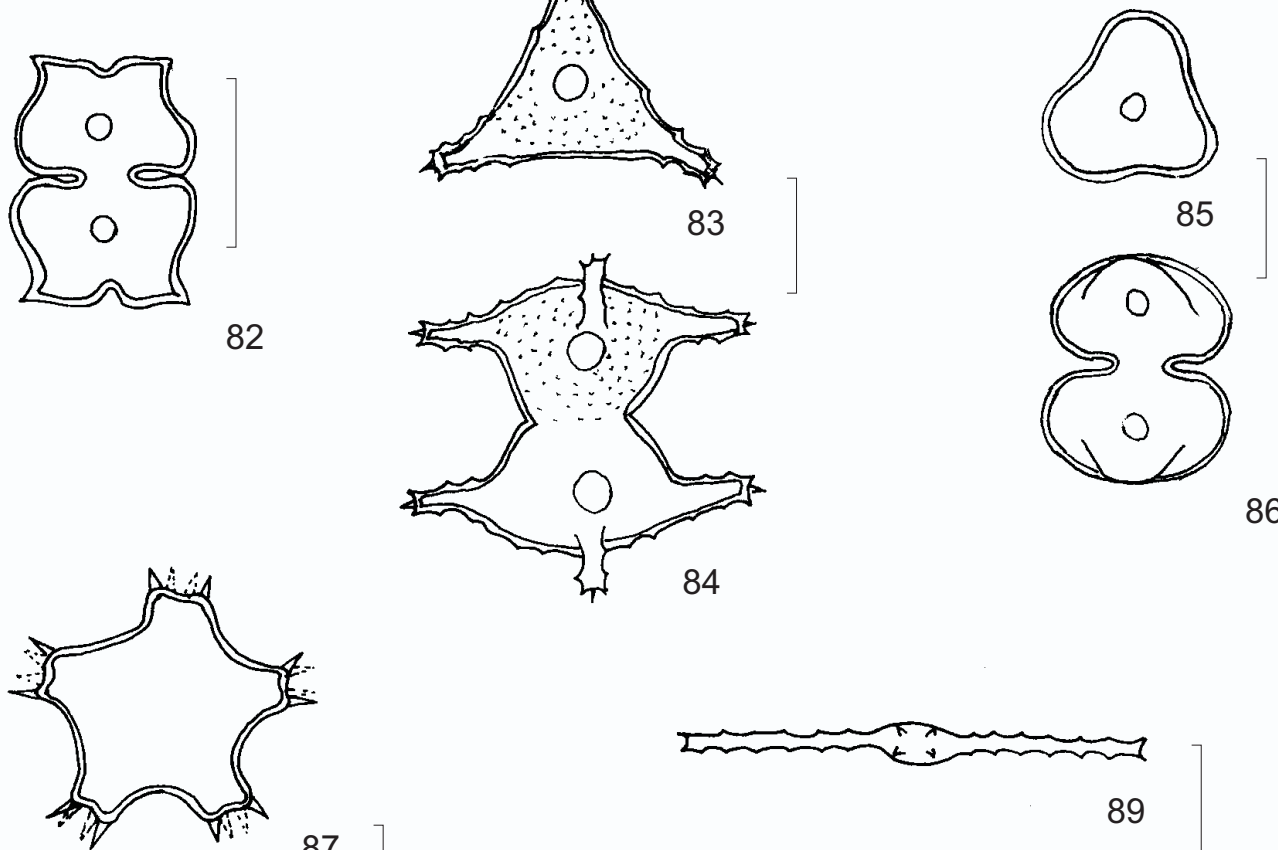

89

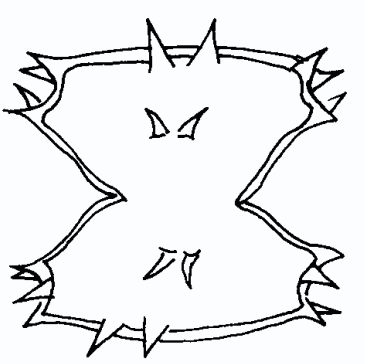

88

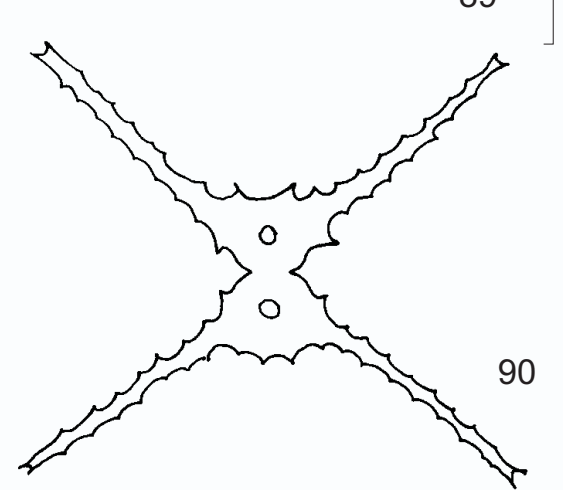

Figs. 74 e 75 - Actinotaenium perminutum. Figs. 76 e 77 - Cosmarium bioculatum var. depressum. Figs. 78 e 79 - C. contractum var. minutum. Figs. 80 e $81-C$. sphagnicolum var. apertum. Fig. 82 - Euastrum binale. Figs. 83 e $84-$ Staurastrum affine. Figs. 85 e $86-$ S. muticum. Figs. 87 e $88-S$. quadrangulare var. contectum. Figs. 89 e $90-S$. quadrinotatum. (Escalas $=10 \mu \mathrm{m}$.) 
Acta Soc. Sci. fenn. 2(6): 30, Nova sér. B, Fig. 258, 1945.

Células 1,2-1,5 vez mais largas que longas; seno aberto; semicélulas trapezoidais, ápice entumescido, com 4 espinhos opostos 2 a 2, margens laterais prolongadas em 2 processos denticulados, divergentes, terminando em 2 dentes; vista vertical elíptica, ângulos projetados em longos processos. Compr. das células 37,5-41 $\mu \mathrm{m}$ (c/ proc.), 10-12 $\mu \mathrm{m}$ (s/ proc.), larg. 40-60 $\mu \mathrm{m}$ (c/ proc.), istmo 4-7 $\mu \mathrm{m}$.

Staurastrum tetracerum (Kütz.) Ralfs var. tortum (Teil.) Borg. (Figs. 91-92)

Sjon TaKerna Fauna och Flora, 4: 22, pl. 2, Fig. 22, 1921.

Células tão largas quanto longas; seno aberto; semicélulas trapeziformes, torcidas, margens laterais prolongadas em 2 processos denticulados, divergentes, terminando em 3 dentes; vista vertical elíptica, ângulos projetados em longos processos divergentes. Compr. das células 22-28 $\mu \mathrm{m}$ (c/ proc.), 10-14 $\mu \mathrm{m}$ (s/ proc.), larg. 22-28 $\mu \mathrm{m}$ (c/ proc.), istmo $3-4,5 \mu \mathrm{m}$.

Staurodesmus cuspidatus (Bréb.) Teil. var. curvatus (West) Teil. (Figs. 93-94)

Ark. Bot., 6 (11): 535, pl. 9, Fig. 12, pl. 10, Figs. 3 e 4, 1967.

Células 1,5-1,6 vez mais largas que longas; seno aberto, cilíndrico; semicélulas piramidais truncadas, ângulos continuados em espinhos paralelos a divergentes; vista vertical triangular, margens laterais côncavas; parede celular lisa. Compr. das células 19-21 $\mu \mathrm{m}$, larg. 29-34 $\mu \mathrm{m}$ (c/ esp.), istmo 4-5,5 $\mu \mathrm{m}$. 95-96)

Staurodesmus dejectus (Bréb.) Teil. (Figs.

Rapp. VII Congr. int. Bot., 128, 1954.

Células tão longas quanto largas; seno aberto; semicélulas piramidais truncadas, margem apical levemente côncava, lateral convexa, ângulos com 1 espinho reto, voltado para cima; vista vertical triangular, margens laterais côncavas, ângulos arredondados com 1 espinho; parede celular lisa. Compr. das células 10-15 $\mu \mathrm{m}$ (c/ esp.), 10-12 $\mu \mathrm{m}$ (s/ esp.), larg. 12-16 $\mu \mathrm{m}$ (c/ esp.), istmo 4,5-6 $\mu \mathrm{m}$.

Staurodesmus lobatus (Borg.) Bourr. var. ellipticus (Frits. \& Rich.) Teil. f. minor (G. M. Smith) Teil. (Figs. 97-98)

Ark. Bot. 6(11): 586, pl. 24, Fig. 8, 1967.

Células 1,1-1,5 vez mais longas que largas; seno aberto; semicélulas elípticas com 1 diminu- to espinho no eixo maior da elipse, geralmente voltado para a semicélula oposta; vista vertical elíptica; parede celular lisa. Compr. das células 13-16 $\mu \mathrm{m}$, larg. 7,5-14 $\mu \mathrm{m}$ (c/ esp.), istmo 5-6 $\mu \mathrm{m}$.

Staurodesmus mamillatus (Nordst.) Teil. var. maximus (W.West) Teil. (Figs. 99-100)

Ark. Bot. 6(11): 537, pl. 10, Figs. 6 e 7, 1967.

Células 1,8-2,2 vezes mais largas que longas; seno aberto, cilíndrico; semicélulas piramidais truncadas, margem apical convexa, ângulos inflados, cada um com 1 espinho longo, paralelo a divergente; vista vertical triangular; parede celular lisa. Compr das células 20-24 $\mu \mathrm{m}$ (c/ esp.), 19$21 \mu \mathrm{m}$ (s/ esp.), larg. 40-45 $\mu \mathrm{m}$ (c/ esp.), istmo 4-6 $\mu \mathrm{m}$.

Staurodesmus phimus (Turn.) Thom. (Figs. 101-102)

Acta phytogeogr. Suec., 42: 75, pl. 23, Fig. 22, 1959.

Células tão longas quanto largas, até um pouco mais largas que longas, seno aberto; semicélulas trapeziformes, margem apical côncava, margens laterais convexas, ângulos afilados abruptamente, terminando em curto espinho divergente; vista vertical fusiforme. Compr. das células 24-28,5 $\mu \mathrm{m}$ (c/ esp.), 18-22 $\mu \mathrm{m}$ (s/ esp.), larg. 22-28,5 $\mu \mathrm{m}$ (c/ esp.), istmo $6,5-8,5 \mu \mathrm{m}$.

\section{Classe Euglenophyceae}

Lepocinclis fusiformis (H. J. Cart.) Lemm. emend. Conr. (Fig. 103)

Arch. Protistenk., 82(2): 225, Fig. 30, 1934.

Células citriformes, razão comprimento/largura $=1,3-1,5$; pólo anterior acuminado, posterior projetado em curto processo caudal acuminado ou mamilado; película com estrias levógiras; cloroplastos numerosos, discóides, $c a .2 \mu \mathrm{m}$ de diâm.; 2 grãos de paramido, anelares, laterais, opostos, 9-15 $\mu \mathrm{m}$ de diâm. Compr. das células 30-35 $\mu \mathrm{m}$ (c/ proc.), larg. 20-26 $\mu \mathrm{m}$.

Lepocinclis ovum (Ehrenb.) Lemm. (Fig. 104) KryptoFlora Brand., v. 3, p. 504, Fig. 13, 1910.

Células ovadas, $\mathrm{Rc} / \mathrm{l}=1,3-1,4$; pólo posterior mamilado; película hialina, rígido, estrias levógiras; cloroplastos numerosos, discóides, $c a .2 \mu \mathrm{m}$ de diâm.; 2 grãos de paramido anulares, alongados, laterais, opostos, ca. $5 \mu \mathrm{m}$ de compr. e $6 \mu \mathrm{m}$ de larg. Compr. das células 20-27 $\mu \mathrm{m}$ (c/ proc.), larg. 14-20 $\mu \mathrm{m}$.

Phacus contortus Bourr. (Fig. 105) 

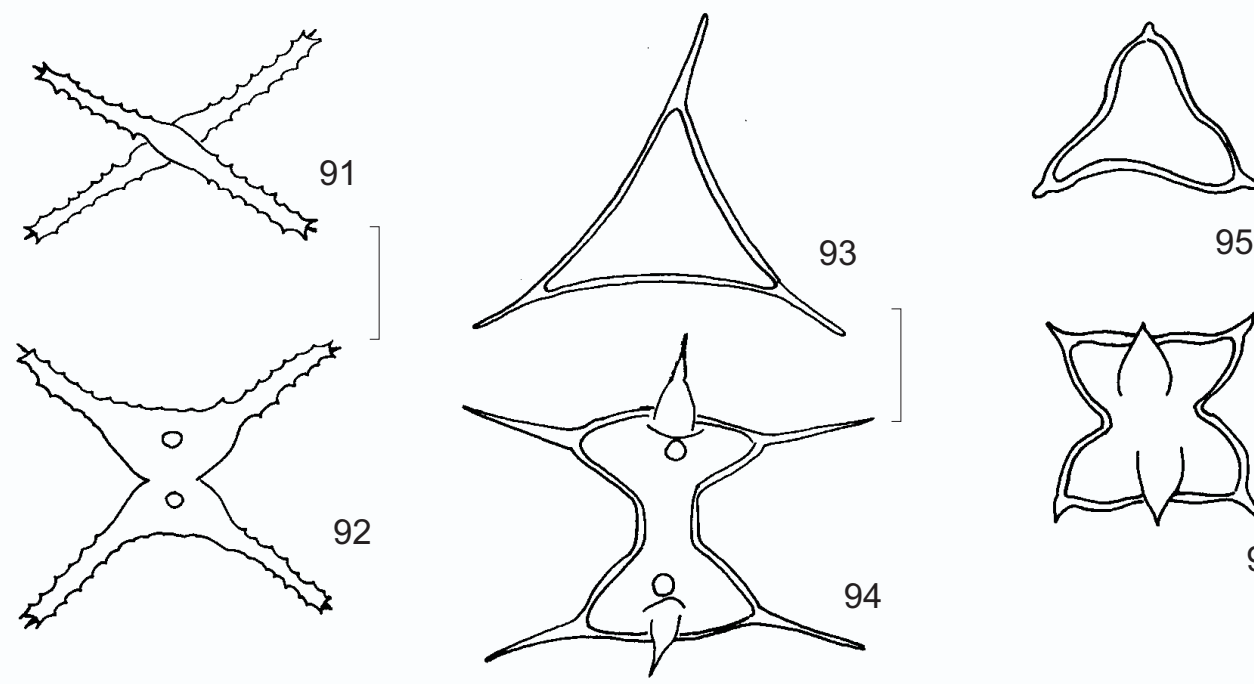

95
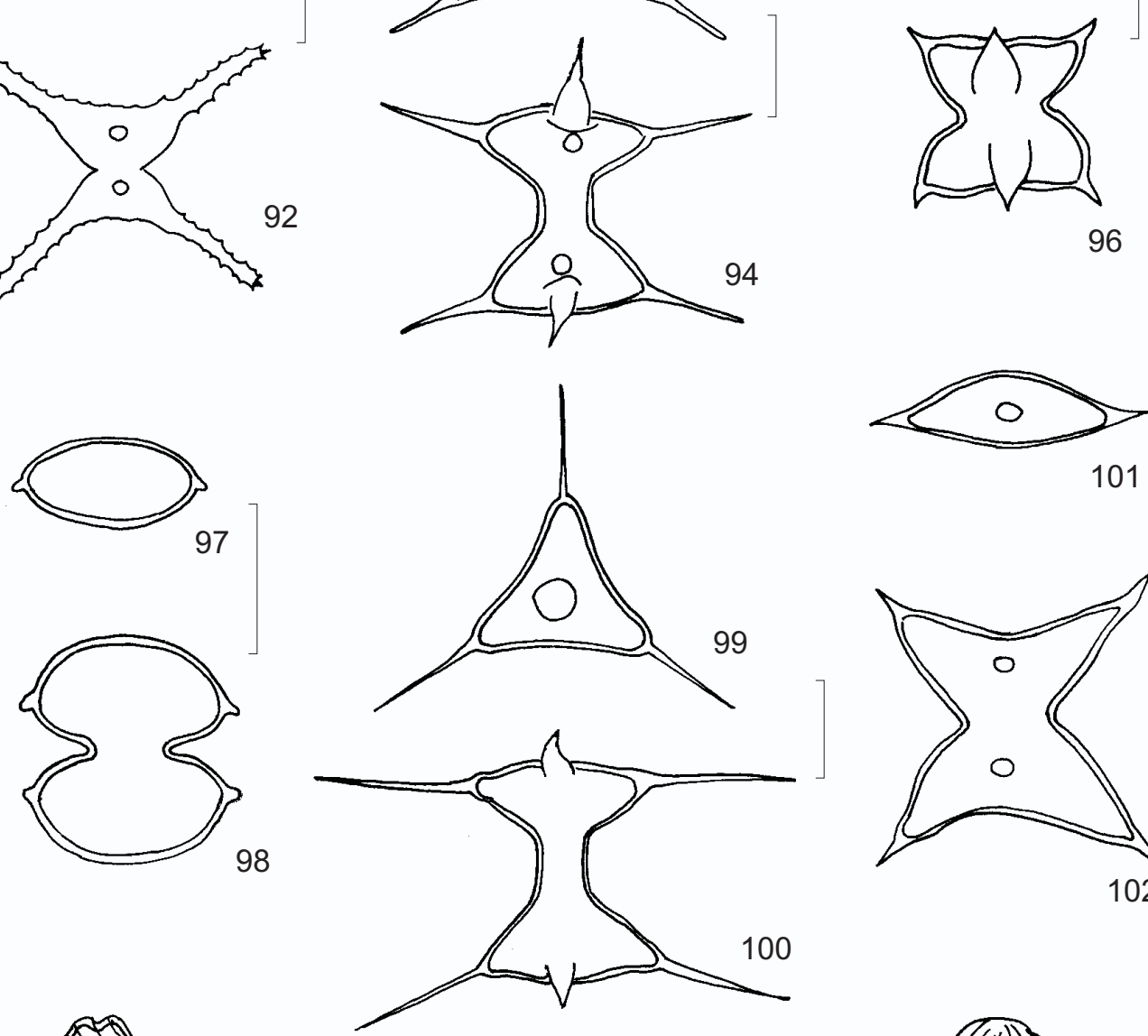

101
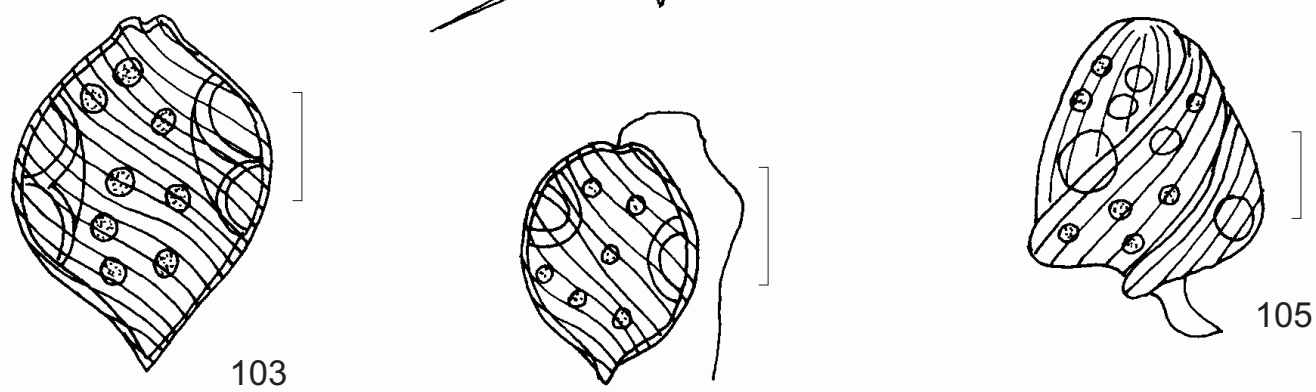

104

Figs. 91 e 92 - Staurastrum tetracerum var. tortum. Figs. 93 e 94 - Staurodesmus cuspidatus var. curvatus. Figs. 95 e $96-S$. dejectus. Figs. 97 e $98-$ S. lobatus var. ellipticus f. minor. Figs. 99 e $100-S$. mamillatus var. maximus. Figs. 101 e $102-$ S. phimus. Figs. 103 - Lepocinclis fusiformis. Fig. $104-$ L. ovum. Fig. 105 - Phacus contortus. (Escalas = $10 \mu \mathrm{m}$. 
In: Bourrelly \& Manguin, Algues d'Eau douce Guad. Dép., p. 177, pl. 22, Figs. 271-277, 1952.

Células ovadas, assimétricas, torcidas, $\mathrm{Rc} /$ $1=1,2-1,5$; pólo posterior atenuado abruptamente em processo caudal cônico, curvo, $c a .10 \mu \mathrm{m}$ de compr.; lados dorsal e ventral sulcados, dividindo a célula em duas porções desiguais; película hialina, estrias longitudinais; cloroplastos numerosos, discóides, $c a .2 \mu \mathrm{m}$ de diâm.; grãos de paramido 2 , discóides, laterais, simétricos 8-9 $\mu \mathrm{m}$ de diâm. Compr. das células 35-48 $\mu \mathrm{m}$ (c/ proc.), larg. 30$35 \mu \mathrm{m}$.

Phacus longicauda (Ehrenb.) Duj. (Fig. 106)

Hist. nat. Zoophytes, p. 337, pl. 5, Fig. 6, 1841.

Células obovadas, levemente torcidas, $\mathrm{Rc} /$ $1=2,5-2,7$; pólo anterior arredondado; pólo posterior atenuado gradualmente em processo caudal, 40-50 $\mu \mathrm{m}$ de compr.; película hialina, estrias longitudinais; cloroplastos numerosos discóides, ca. $2 \mu \mathrm{m}$ de diâm.; 2 grãos de paramido discóides, sobrepostos, centrais, 9-12 $\mu \mathrm{m}$ de diâm., outros menores dispersos. Compr. das células 97-116 $\mu \mathrm{m}$ (c/ proc.), larg. 37-45 $\mu \mathrm{m}$.

Phacus pleuronectes (O. F. Müller.) Duj. (Fig. 107)

Hist. nat. Zoophytes, p. 336, pl. 5, Fig. 5, 1841.

Células arredondadas, levemente torcidas na região posterior, $\mathrm{Rc} / 1=1,2-1,4$; pólo posterior atenuado abruptamente em processo caudal curvo, 5-8 $\mu \mathrm{m}$ de compr.; película hialina, estrias longitudinais; cloroplastos numerosos, discóides, $c a$. $2 \mu \mathrm{m}$ de diâm.; 2 grãos de paramido discóides, sobrepostos, centrais, de tamanhos desiguais. Compr. das células 35-42 $\mu \mathrm{m}$ (c/ proc.), larg. 26$30 \mu \mathrm{m}$.

Phacus tortus (Lemm.) Skv. (Fig. 108)

Ber. dt. bot. Ges. Berlin, 46(2): 110, pl. 2, Fig. 9 e 10, 1928.

Células obovadas, torcidas, $\mathrm{Rc} / 1=2,6-3,2$; pólo anterior conicamente arredondado, posterior atenuado terminando em processo caudal reto, 20$35 \mu \mathrm{m}$ de compr.; película estriada espiraladamente; cloroplastos numerosos, discóides, 1-1,5 $\mu \mathrm{m}$ de diâm.; 1-2 grãos de paramido discóides, sobrepostos, centrais, 6-8 $\mu \mathrm{m}$ de diâm. Compr. das células 65-102 $\mu \mathrm{m}$ (c/ proc.), larg. 24-35 $\mu \mathrm{m}$.

Trachelomonas armata (Ehrenb.) Stein (Fig. 109)
Infus. 3, pl. 22, Figs. 37-38, 1878.

Lóricas ovadas; pólos arredondados, poro com espessamento anelar; colo ausente; parede pontuada; espinhos cônicos distribuídos por toda a superfície da lórica, os maiores concentrados no pólo posterior. Compr. das lóricas 34-38 $\mu \mathrm{m}$, larg. 26-30 $\mu \mathrm{m}$

Trachelomonas armata (Ehrenb.) Stein $\mathrm{f}$. inevoluta Defl. (Fig. 110)

Révue gén. Bot., 38: 689, pl. 6, Figs. 321 e 325, 1926.

Lóricas oblongas; pólo com espessamento anelar; parede pontuada. Compr. das lóricas 30$32 \mu \mathrm{m}$, larg. 22-26 $\mu \mathrm{m}$.

Trachelomonas cervicula Stokes (Fig. 111)

Proc. Am. Philos. Soc., 28: 75, Fig. 5, 1890.

Lóricas esféricas a subesféricas; colo interno reto; parede pontuada; numerosos cloroplastos discóides, $c a .2 \mu \mathrm{m}$ de diâm.; grãos de paramido numerosos, em forma de bastonetes, $c a .2 \mu \mathrm{m}$ de compr. Diâm das lóricas 14-18 $\mu \mathrm{m}$.

Trachelomonas raciborskii Wolosz. (Fig. 112) 1912.

Bull. Ac. Sci. Cracovie., 1: 696, Fig. 197,

Lóricas oblongo-elípticas; colo baixo com bordo denteado; parede pontuada, com espinhos apenas nos pólos. Compr. das lóricas 30-35 $\mu \mathrm{m}$, larg. 24-28 $\mu \mathrm{m}$.

Trachelomonas similis Stokes (Fig. 113)

Proc. Am. Phil. Soc., 28: 76, Fig. 12, 1890.

Lóricas oblongas; colo cilíndrico, curvo, $c a$. $3 \mu \mathrm{m}$ de compr. e $c a$. de 5,5 $\mu \mathrm{m}$ de larg.; parede pontuada; cloroplastos discóides, $c a$. 1,5 $\mu \mathrm{m}$ de diâm.; grãos de paramido alongados, $c a$. 2,5 $\mu \mathrm{m}$ de compr. Compr. das lóricas 22-27,5 $\mu \mathrm{m}$, larg. $18-21 \mu \mathrm{m}$.

Trachelomonas volvocina Ehrenb. (Fig. 114)

Infus., p. 18, pl. 2, Fig. 29, 1838.

Lóricas esféricas; espessamento anelar presente; colo ausente; parede celular lisa; 2 cloroplastos em escudo 2,5-6 $\mu \mathrm{m}$ de compr. e 3$4 \mu \mathrm{m}$ de larg.; grãos de paramido numerosos, em bastonetes, 1-1,5 $\mu \mathrm{m}$ de compr. Diâm. das lóricas 8-10 $\mu \mathrm{m}$.

\section{Classe Bacillariophyceae}

Aulacoseira granulata (Ehrenb.) Simons. (Figs. 115-116)

Bacillaria, 2: 58, 1979. 
Filamentos longos, células cilíndricas, freqüentemente com dentes marginais; sulco pouco profundo de recorte angular; 2-4 espinhos de tamanhos diferentes; manto reto, estrias grosseiras, oblíquas ao eixo pervalvar. Compr. das frústulas $25-28 \mu \mathrm{m}$, larg. 4,5-6,5 $\mu \mathrm{m} ; 8-12$ aréolas em $10 \mu \mathrm{m}$. 118)

Cyclotella stelligera Cleve \& Grunn. (Fig.

In: P. T. Cleve, Bih. k. svenska VetenskAkad. Handl., 18: 22, pl. 5, Figs. 63a-c, 1881.

Células isoladas, valvas circulares, região marginal com costelas radiadas, região central com 1 ponto isolado circundado por 7 pontos, formando uma roseta. Diâm. das frústulas 7,5-11 $\mu \mathrm{m} ; 10$ costelas em $10 \mu \mathrm{m}$.

Urosolenia eriensis (H. L. Smith) Round \& Crawf. (Fig. 117)

In: Round, Crawford \& Mann, The Diatoms, p. 324, 1990.

Células isoladas, cilíndricas, pólos cônicos, com setas. Compr. das frústulas 32-64 $\mu \mathrm{m}$, larg. 4,5-5 $\mu \mathrm{m}$; setas $15-30 \mu \mathrm{m}$; 3-4 bandas intercalares em $10 \mu \mathrm{m}$.

\section{Classe Xanthophyceae} 119)

Goniochloris mutica (A. Braun) Fott (Fig.

Preslia, 32: 146, Figs. 2 e 3a, 1960.

Células isoladas, 3 -anguladas, margens côncavas, ângulos arredondados; 2-3 cloroplastos parietais. Larg. das células 7-9 $\mu \mathrm{m}$.

Tetraedriella spinigera Skuja (Fig. 120)

Symb. bot. upsal., 9(3): 243, pl. 36, Fig. 6, 1948.

Células irregularmente tetraédricas, margens geralmente convexas, ângulos agudos, com 1 espinho; 5-7 cloroplastos parietais, discóides; parede hialina. Larg. das células 15-17 $\mu \mathrm{m}$; compr. dos espinhos 6-7 $\mu \mathrm{m}$.

Tetraplektron tribulus (Pasch.) Loebl. (Fig.

Süsswass.-Flora Mitteleuropa, v. 3, p. 222, Fig. 269, 1978.

Células isoladas, tetraédricas, ângulos terminando em processos longos ; 5-7 cloroplastos discóides. Larg. das células com processos 16-20 $\mu \mathrm{m}$.

\section{Classe Chrysophyceae}

Chromulina microplankton (Pasch.) Pasch.

(Fig. 122)
Süsswass.-Flora v. 2, part 2, p. 15, Fig. 13, 1913.

Células isoladas, ovadas; 1 cloroplasto; 1 flagelo apical, parede celular lisa. Compr. das células 2,5-3,5 $\mu \mathrm{m}$, larg. 2-2,5 $\mu \mathrm{m}$.

Chrysococcus punctiformis Pasch. (Fig. 123)

Ber. dt. bot. Ges. 29: 529, pl. 19, Fig. 18ad, 1911.

Lóricas isoladas, esféricas, lisas; 1 cloroplasto equatorial, em anel; 1 flagelo apical, $c a .4$ vezes o comprimento da lórica. Diâm. das lóricas 2-3 $\mu \mathrm{m}$.

Dinobryon elegantissimum (Kors.) Bourr. (Fig. 124)

Revue algol. Mém. Hors, sér. 1: 165, pl. 2, Figs. 11 e 12, 1957.

Lóricas solitárias, campanuladas, região posterior gradualmente atenuada, margens laterais levemente convexas com ondulações marcadas; Compr. das lóricas 42-55 $\mu \mathrm{m}$, larg. 8-11,5 $\mu \mathrm{m}$; compr. das células 8,5-12 $\mu \mathrm{m}$, larg. 4,5-5,5 $\mu \mathrm{m}$.

Dinobryon sertularia Ehrenb. (Fig. 125)

Phys. Math. Abh. K. Akad. Wiss. Berlin, 1833: 280, 1835.

Colônias ramificadas; ramificações levemente divergentes; lóricas campanuladas, região posterior abruptamente atenuada, margens laterais convexas, lisas. Compr. das lóricas 14,5-20 $\mu \mathrm{m}$, larg. 4-7 $\mu \mathrm{m}$; compr. das células 5-7 $\mu \mathrm{m}$, larg. 2-3 $\mu \mathrm{m}$.

\section{Classe Cryptophyceae}

Chroomonas acuta Uterm. (Figs. 126 e 127)

Arch. Hydrobiol. (supplement.): 5: 399, Fig. 34, 1925 .

Células obovadas em vista lateral, pólo posterior afilado, voltado para a região ventral; 1 cloroplasto lobado, 1 pirenóide dorsal mediano. Compr. das células 7,5-10 $\mu \mathrm{m}$, larg. 3-4,5 $\mu \mathrm{m}$.

Cryptomonas erosa Ehrenb. (Figs. 128 e 129)

Phys. Math. Abh. K. Akad. Wiss. Berlin, 1831: 56, 1832.

Células obovadas a oblongas em vista lateral; pólo anterior truncado-oblíquo, posterior arredondado, às vezes curvo dorsalmente, raramente para o ventre; vistas ventral e dorsal obovadas; 2 cloroplastos dorsiventrais, grãos de amido elípticos variando em número; 1-2 corpúsculos de Maupa anteriores ou posteriores à citofaringe. Compr. das células 21-30 $\mu \mathrm{m}$, larg 9,5-11,5 $\mu \mathrm{m}$. Rc/1 = 2,22,6 . 

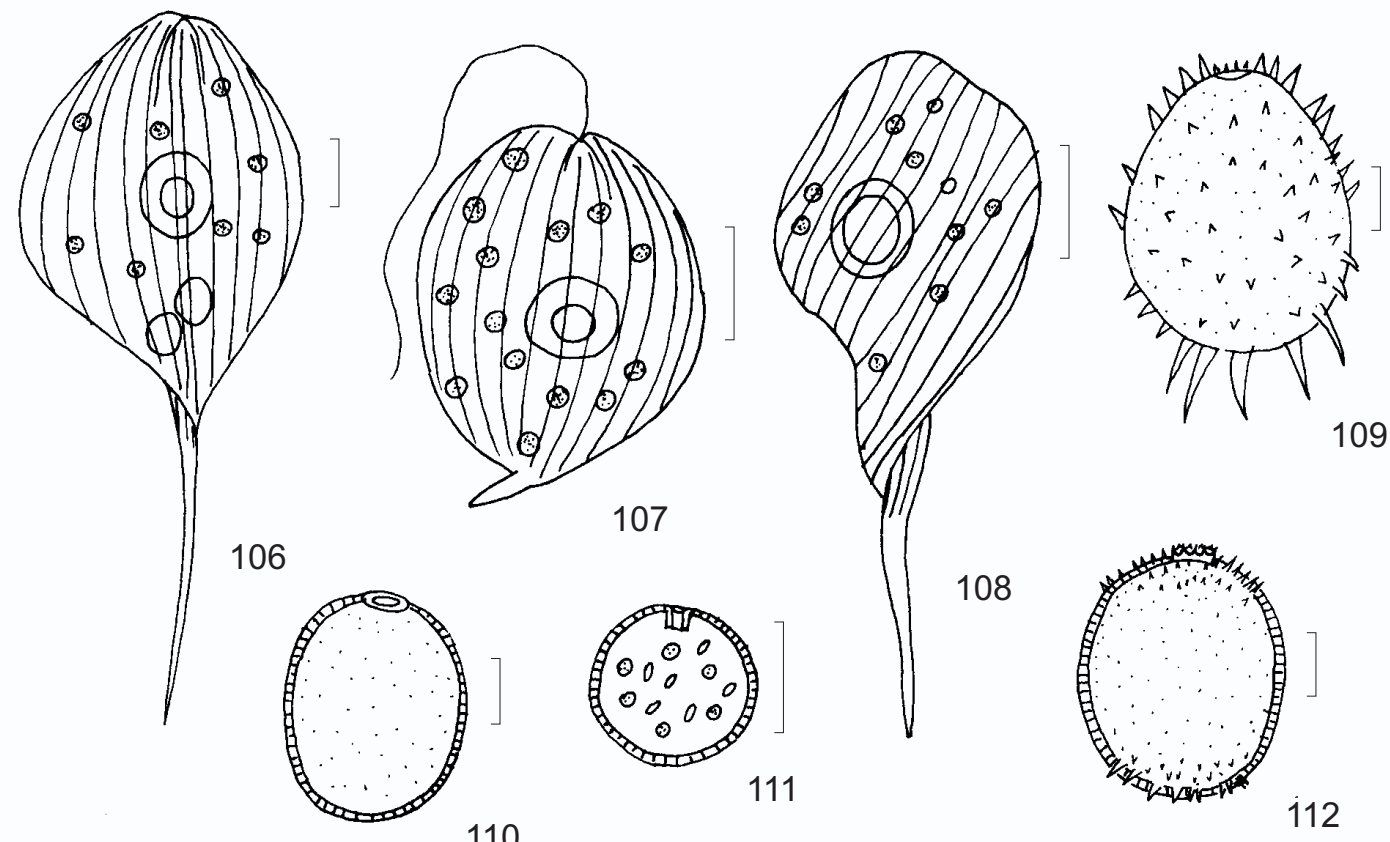

110
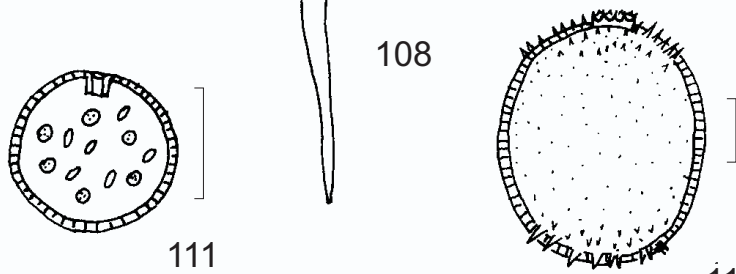

112
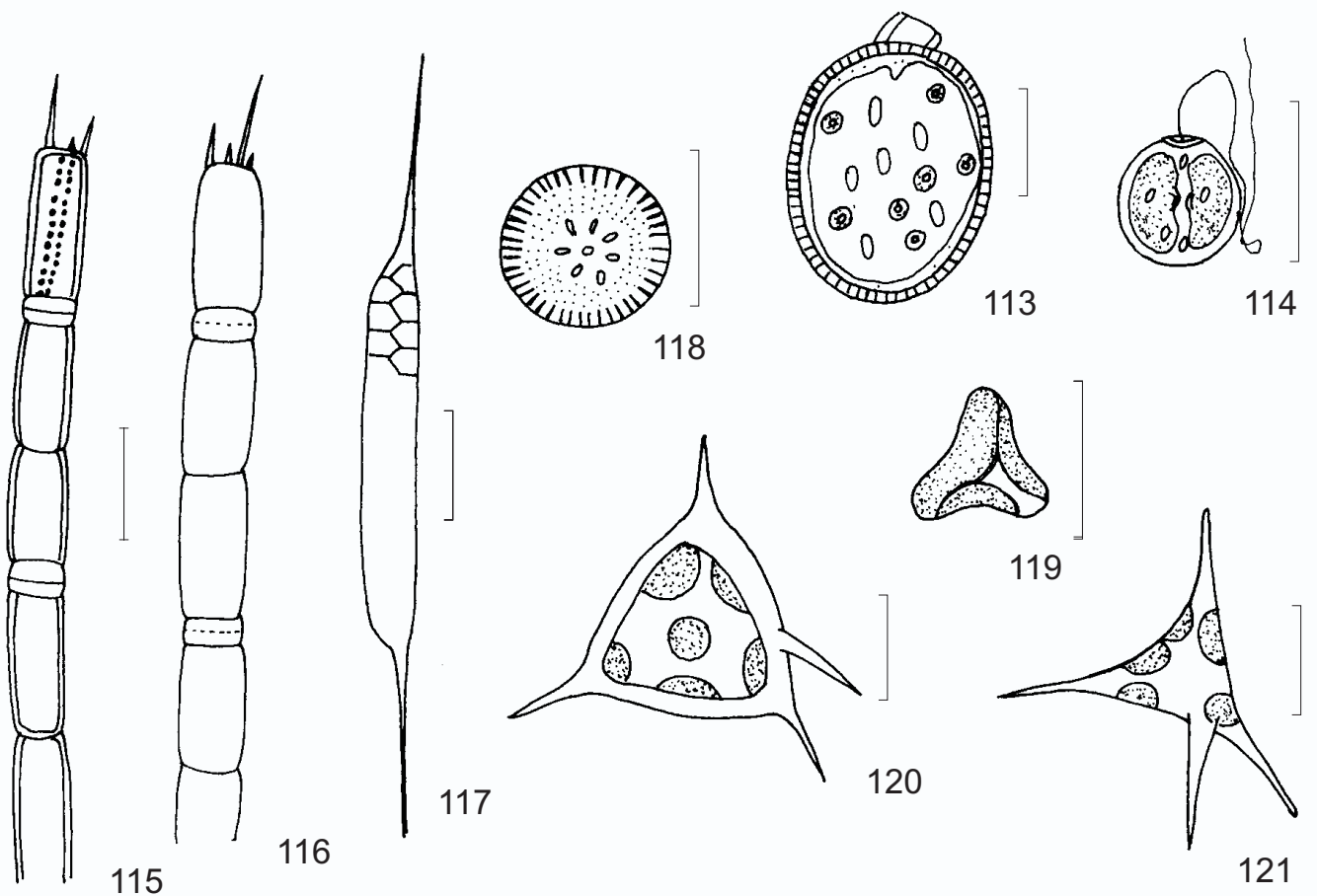

118
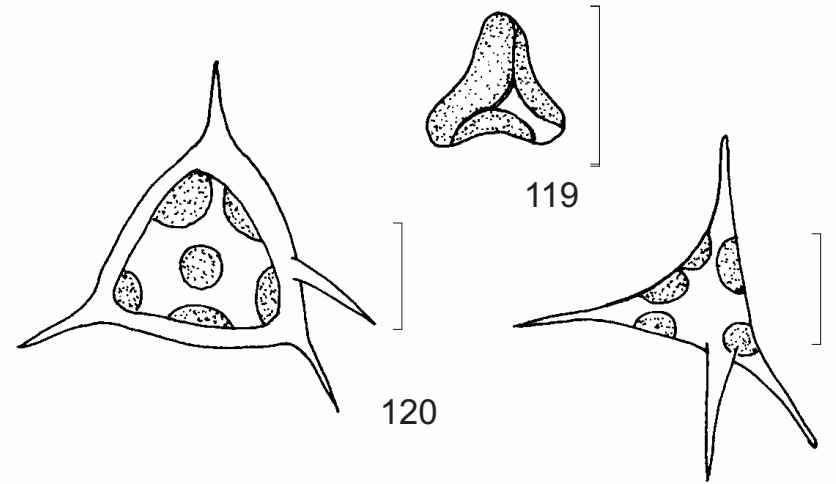

121

Fig. 106 - Phacus longicauda. Fig. 107 - P. pleuronectes. Fig. 108 - P. tortus. Fig. 109 - Trachelomonas armata. Fig. $110-T$. armata f. inevoluta. Fig. $111-T$. cervicula. Fig. $112-T$. raciborskii. Fig. $113-T$. similis. Fig. $114-T$. volvocina. Figs. 115 e 116 - Aulacoseira granulata. Fig. 117 - Urosolenia eriensis. Fig. 118 - Cyclotella stelligera. Fig. 119 - Goniochloris mutica. Fig. 120 - Tetraedriella spinigera. Fig. $121-$ Tetraplektron tribulus. $($ Escalas $=10 \mu \mathrm{m}$.) 

131)

Cryptomonas marssonii Skuja (Figs. 130 e 1948.

Symb. bot. upsal., 9(3): 357, pl. 37, Fig. 41,

Células obovadas em vista lateral; pólo anterior truncado-oblíquo, posterior afilado, curvo dorsalmente; vistas ventral e dorsal obovadas; 2 cloroplastos parietais, laterais, numerosos grãos de amido; 2 corpúsculos de Maupa, posteriores à citofaringe, às vezes centrais. Compr. das células $12-15 \mu \mathrm{m}$, larg. 5,5-7,5 $\mu \mathrm{m}$. Rc/1 = 1,8-2. 133)

Cryptomonas platyuris Skuja (Figs. $132 \mathrm{e}$

Symb. bot. upsal., 9(3): 358, pl. 37, Figs. 37 e 38, 1948.

Células obovadas em vista lateral, às vezes curvas dorsalmente; pólo anterior truncado, posterior arredondado; vistas ventral e dorsal oblongas ou obovadas; 2 cloroplastos dorsiventrais, de disposição reta ou transverso-oblíqua ao eixo longitudinal da célula; grãos de amido e corpúsculos de Maupa não-observados. Compr. das células 30$40 \mu \mathrm{m}$, larg. 12-17,5 $\mu \mathrm{m}$. Rc/l = 2-2,5.

\section{Classe Dinophyceae}

Peridinium umbonatum Stein (Figs. 134 a 137)

Infus., 3(2): pl. 12, Figs. 1-8, 1883.

Células ovadas; epiteca cônica, maior que a hipoteca; hipoteca arredondada; cíngulo helicoidal à esquerda; sulco estendido levemente na epiteca, alargando na hipoteca, atingindo o pólo antapical; poro apical presente; suturas estriadas; epiteca com placas simétricas, sendo 4 apicais, 2 intermediárias e 7 pré-cingulares; hipoteca com placas simétricas, sendo 5 pós-cingulares e 2 antapicais. Compr. das células 20-38 $\mu \mathrm{m}$, larg. 18$34 \mu \mathrm{m}$.

Peridinium volzii Lemm. (Figs. 138 a 141) Abh. nat. Ver. Bremen, 18: 166, 1905.

Células arredondadas; tecas arredondadas, epiteca maior que a hipoteca; cíngulo helicoidal à esquerda; sulco longitudinal desde a epiteca, alargando-se na hipoteca, sem atingir o pólo antapical; suturas estriadas; placas reticuladas; epiteca com 4 placas apicais, 3 intermediárias e 7 précingulares; hipoteca com 5 placas pós-cingulares e 2 antapicais. Compr. das células 25-45 $\mu \mathrm{m}$, larg. $25-45 \mu \mathrm{m}$.
Além dos táxons descritos, 9 foram identificados em nível genérico: Chlamydomonas $\mathrm{sp}_{1}$, Chlamydomonas $\mathrm{sp}_{2}$, Chloromonas $\mathrm{sp}$, Euglena $\mathrm{sp}_{1}$, Euglena $\mathrm{sp}_{2}$, Synedra $\mathrm{sp}$, Mallomonas $\mathrm{sp}$, Peridinium sp, e 3 foram listados em suas respectivas classes: Chlorophyceae, Bacillariophyceae e Dinophyceae.

Os resultados obtidos para os coeficientes fitoplanctônicos nas diferentes amostras, variaram entre 2 e 21 , com média de 3,3, para o Coeficiente Simples; entre 3,7 e 35,0, com média de 5,8, para o Coeficiente Múltiplo; e entre 1 e 2, com média de 1,5, para o Coeficiente de Diatomáceas.

\section{CONSIDERAÇÕES FINAIS}

O fitoplâncton do Lago Monte Alegre esteve constituído por 119 táxons, pertencentes a 9 classes taxonômicas. Dentre os 119 táxons, foram identificadas 93 espécies, 9 variedades e 5 formas taxonômicas. Foram determinados 9 táxons em nível genérico e 3 foram listados apenas em suas respectivas classes.

Do total de táxons registrados, $59 \%$ pertencem à divisão Chlorophyta representada, principalmente, por Chlorococcales (48) e Desmidiales (15), sendo Scenedesmus o gênero mais representativo ( 9 táxons). O predomínio florístico da divisão Chlorophyta já foi registrado em diferentes reservatórios da região Sudeste brasileira (Marinho, 1994).

Segundo alguns autores, lagos tropicais são mais simples (menor número de espécies) do que lagos temperados (Lewis, 1978; Payne, 1986). Para outros, entretanto, não existe qualquer relação entre riqueza de espécies e latitude onde os lagos estão localizados (Kalff \& Watson, 1986).

$\mathrm{Na}$ Tabela 1 são comparados os números totais de espécies e de gêneros do fitoplâncton registrados para o lago Monte Alegre com aqueles obtidos para outros ambientes tropicais, subtropicais e temperados. Foi possível observar elevado número de espécies nos lagos tropicais e subtropicais (70-191), quando comparado aos ambientes temperados (43-91), bem como maior número médio de gêneros (59 para lagos tropicais e subtropicais e 37 para lagos temperados). Os dados observados são contrários aos de Lewis (1978) e de Payne (1986), porém reforçam aqueles obtidos por Huszar (1994, 1996). 


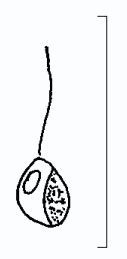

122

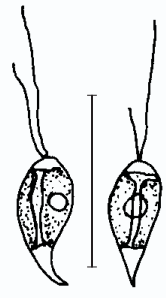

126
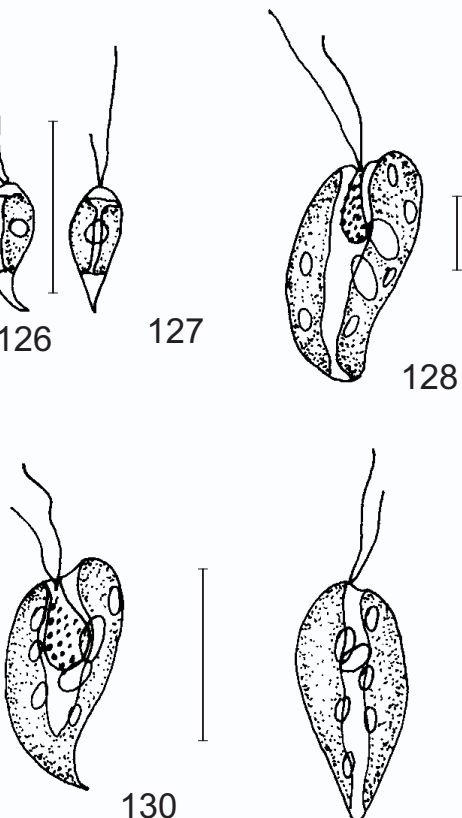

130

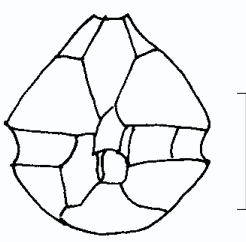

134

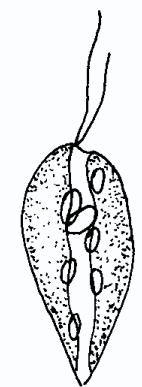

129
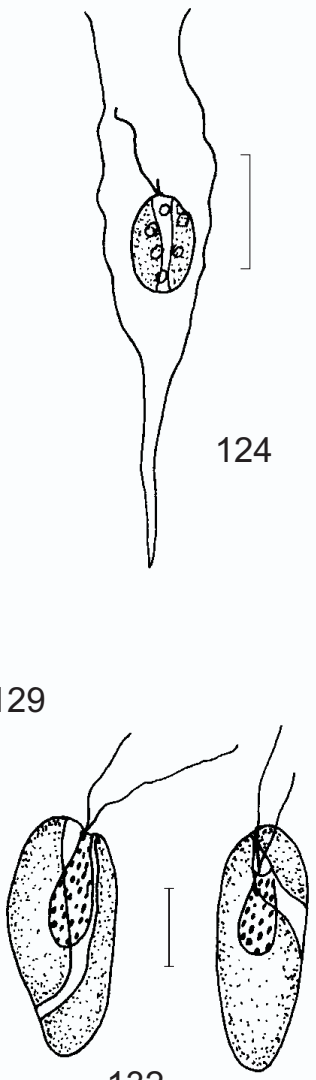

132

133

131
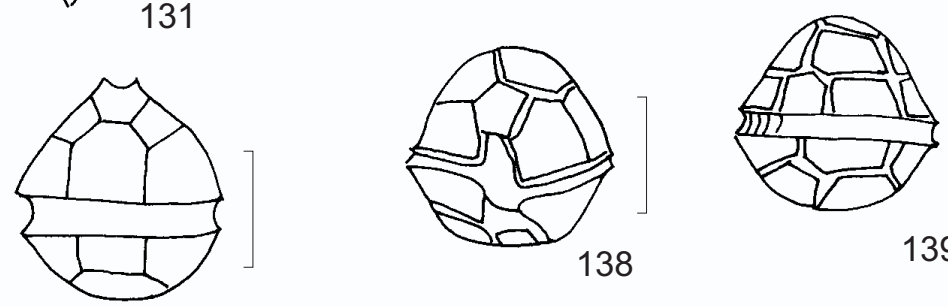

139

135
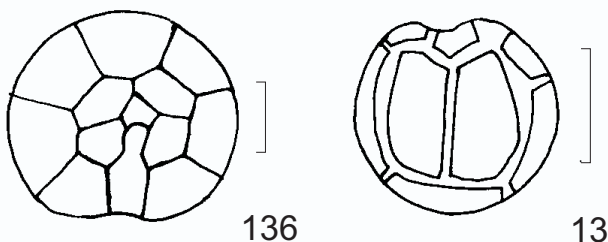

137
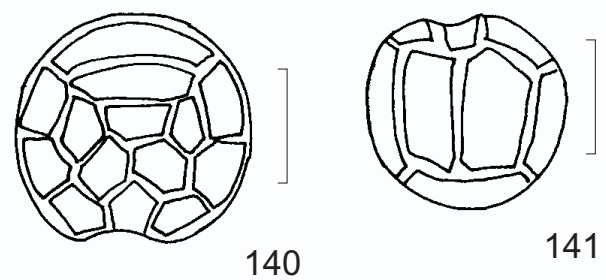

141

Fig. 122 - Chromulina cf. microplankton. Fig. 123 - Chrysococcus punctiformis. Fig. 124 - Dinobryon elegantissimum. Fig. $125-D$. sertularia. Figs. 126 e $127-$ Chroomonas acuta. Figs. 128 e $129-$ Cryptomonas erosa. Figs. 130 e $131-C$. marssonii. Figs. 132 e $133-$ C. platyuris. Figs. 134 a $137-$ Peridinium umbonatum. Figs. 138 a $141-P$. volzii. (Escalas $=10 \mu \mathrm{m}$.) 
TABELA 1

Comparação entre o número total de gêneros e espécies do fitoplâncton registrados para o lago Monte Alegre com aqueles de outros lagos tropicais, subtropicais e temperados.

\begin{tabular}{|c|c|c|}
\hline Lagos & No espécies & $\mathbf{N}^{o}$ gêneros \\
\hline \multicolumn{3}{|l|}{ Tropicais e subtropicais } \\
\hline Monte Alegre & 119 & 61 \\
\hline Batata ${ }^{1}$ (Pará) & 172 & 93 \\
\hline Infernão ${ }^{2}$ (São Paulo) & 191 & 50 \\
\hline Paranoá ${ }^{3}$ (Brasília) & 72 & 35 \\
\hline Matadores $^{4}$ (Argentina) & 124 & 66 \\
\hline Oloiden $^{5}$ (Quênia) & 96 & 49 \\
\hline Naivasha ${ }^{6}$ (Quênia) & 136 & 81 \\
\hline Valencia $^{7}$ (Venezuela) & 82 & 51 \\
\hline Lanao $^{8}$ (Filipinas) & 70 & 43 \\
\hline MÉDIA & 118 & 59 \\
\hline \multicolumn{3}{|l|}{ Temperados } \\
\hline Ontário ${ }^{9}$ (Canadá) & 69 & 48 \\
\hline Erie $^{10}$ (Canadá) & 43 & 19 \\
\hline Huron $^{11}$ (Canadá) & 91 & 42 \\
\hline Superior $^{12}$ (Canadá) & 77 & 33 \\
\hline Michigan $^{13}$ (Canadá) & 69 & 35 \\
\hline Vilá $^{14}$ (Espanha) & 54 & 32 \\
\hline Banyoles $^{15}$ (Espanha) & 77 & 47 \\
\hline MÉDIA & 69 & 37 \\
\hline \multicolumn{3}{|c|}{$\begin{array}{l}1=\text { Huszar (1994); } 2 \text { = Dias (com. pess.); } 3=\text { Branco (1991); } 4 \text { = García de } \\
\text { Emiliani (1980); } 5 \text { e } 6=\text { Kalff \& Watson (1986); } 7=\text { Lewis \& Riehl (1982); } \\
8=\text { Lewis (1978); } 9 \text { a } 13=\text { Munawar \& Munawar (1986); } 14 \text { = García de } \\
\text { Emiliani (1973); } 15 \text { = Planas (1973). }\end{array}$} \\
\hline
\end{tabular}

As espécies que compõem o fitoplâncton são largamente utilizadas para a avaliação do estado trófico dos ecossistemas aquáticos continentais. Nygaard (1949) criou coeficientes planctônicos baseados na relação entre diferentes grupos de algas, para caracterizar o grau de trofia desses ambientes. Limitações na utilização desses coeficientes foram descritas em Brook (1981), mas outros autores têm salientado sua adequação em avaliações de níveis tróficos (Nygaard, 1991).

Diferentes variáveis foram analisadas para a caracterização trófica do lago Monte Alegre (Silva, 1995). No presente trabalho, todos os resultados obtidos a partir dos coeficientes fitoplanctônicos caracterizaram a flora do lago em estudo como típica de ambientes eutróficos.

Agradecimentos - À Dra. Marlene Arcifa, da USP de Ribeirão Preto, pela oportunidade de participar do Projeto Monte Alegre; às professoras do Museu Nacional/UFRJ, Dra. Vera Lúcia Huszar, pela orientação, e Dra. Mariângela Menezes, pela elaboração das figuras, e à CAPES, pelo auxílio através de Bolsa de Mestrado. Apoio da FUJB (Proc. 4650-7 e 5467-4).

\section{REFERÊNCIAS BIBLIOGRÁFICAS}

ARCIFA, M. S., GOMES, E. A. T. \& MESCHIATTI, A. J., 1992, Composition and fluctuations of the zooplankton of a tropical Brazilian reservoir. Arch. Hydrobiol., 123(4): 479-495.

ARCIFA, M. S., MESCHIATTI, A. J. \& GOMES, E. A. T., 1990, Thermal regime and stability of a shallow tropical reservoir: lake Monte Alegre, Brazil. Rev. Hydrobiol., Trop., 23(4): 271-281.

ARCIFA, M. S. \& MESCHIATTI, A. J., 1993, Distribution and feeding ecology of fishes in a brazilian reservoir: lake Monte Alegre. Interciência, 18(6): 302-313.

ARCIFA, M. S. \& MESCHIATTI, A. J., 1996, Tilapia rendalli in the lake Monte Alegre, a case of planktivory. Acta Limnol. Brasil., 8: 221-229. 
BRANCO, C. W. C., 1991, A comunidade planctônica e a qualidade da água no lago Paranoá, Brasília, DF, Brasil. Dissertação de Mestrado, Brasília, UnB, 341p.

BROOK, A. J., 1981, The biology of Desmids. Oxford, Black. Sci. Publ., 276p.

GARCÍA DE EMILIANI, M. O., 1973, Fitoplancton de la laguna del Vilá (Gerona, España). Oecol. Aquat., 1: 107155 .

GARCÍA DE EMILIANI, M. O., 1980, Fitoplancton de una laguna del valle aluvial del Paraná Médio ("Los Matadores"), Santa Fé, Argentina; I. Estructura y distribución en relación a factores ambientales. Ecologia, 4: 127-140.

GODINHO-ORLANDI, M. J. L. \& ARCIFA, M. S., 1990, Estrutura da comunidade planctônica de um reservatório eutrófico tropical, lago Monte Alegre, Estado de São Paulo. Relatório $n^{\underline{0}} 2,108 \mathrm{p}$.

GOMES, E. A. T., 1991, Microorganismos planctônicos (bactérias e protozoários) em um reservatório tropical densidade, biomassa, composição e distribuição temporal e espacial. Dissertação de Mestrado, São Carlos, SP, UFSCar, 125p

HUSZAR, V. L. M., 1994, Fitoplâncton de um lago amazônico impactado por rejeito de bauxita (Lago Batata, Pará, Brasil): estrutura da comunidade, flutuações espaciais e temporais. Tese, São Carlos, SP, UFSCar, 328p.

HUSZAR, V. L. M., 1996, Floristic composition and biogeographical aspects of the phytoplankton of an Amazonian floodplain lake (Lake Batata, Pará, Brasil). Acta Limnol. Brasil., 8: 127-136.

KALFF, J. \& WATSON, S., 1986, Phytoplankton and its dynamics in two tropical lakes: a tropical and temperate zone comparison. Hydrobiol., 138: 161-176.

LEWIS-JR., W. M., 1978, A compositional, phytogeographical and elementary structural analysis of the phytoplankton in a tropical lake: lake Lanao, Philippines. J. Ecol., 66: 213-226.

LEWIS-JR., W. M., 1983, A revised classification of lakes based on mixing. Can. J. Fish. Aquat. Sci., 40: 17791787.

LEWIS-JR., W. M. \& RIEHL, W., 1982, Phytoplankton composition and morphology in Lake Valencia, Venezuela. Int. Revue Ges. Hydrobiol. Hydrogr., 67(3): 297-322.

MARINHO, M. M., 1994, Dinâmica da comunidade fitoplanctônica de um pequeno reservatório raso, densamente colonizado por macrófitas aquáticas submersas (Açude do Jacaré, Mogi-Guaçu, SP, Brasil). Dissertação de Mestrado, São Paulo, USP, 150p.
MESCHIATTI, A. J., GOMES, E. A. T., LANG, L. V., RODRIGUES, R. A. \& HAMASAKI, R. M., 1986, Estudos limnológicos no lago da Fazenda Monte Alegre, Ribeirão Preto, SP. Monografia de Bacharelado, Ribeirão Preto, SP, USP, 133p.

MUNAWAR, M. \& MUNAWAR, I. F., 1986, The seasonality of phytoplankton in the North American Great Lakes, a comparative synthesis. Hydrobiologia, 138: 88-115.

NIMER, E., 1989, Climatologia do Brasil. 2a ed., Rio de Janeiro, IBGE, 422p.

NYGAARD, G., 1949, Hydrobiological studies on some Danish ponds and lakes. Part II. The quociente hypothesis and some new or little know phytoplankton organisms. K. Svenska Danke VidenskAkad. Selskab., 7: 1-293.

NYGAARD, G., 1991, Seasonal periodicity of planktonic desmids in oligotrophic lake Grane Langso, Denmark. Hydrobiologia, 211: 195-226.

PAYNE, A. I., 1986, The ecology of tropical lakes and rivers. New York, John Willey, 301p.

PLANAS, M. D., 1973, Composición, ciclo y productividad del fitoplancton del lago de Banyoles. Oecol. Aquat., 1: 3-106.

SILVA, L. H. S., 1995, Variabilidade temporal na estrutura da comunidade fitoplanctônica de um reservatório eutrófico - lago Monte Alegre, Ribeirão Preto, São Paulo, Brasil. Dissertação de Mestrado, Rio de Janeiro, Museu Nacional, UFRJ, 143p.

SILVA, M. H. L., 1989, Composição e variação da densidade e biomassa da comunidade zooplanctônica no lago Monte Alegre. Monografia de Bacharelado, Ribeirão Preto, SP, USP, $55 \mathrm{p}$

TUNDISI, J. G., 1985, Represas artificiais: perspectivas para o controle e manejo da qualidade da água para usos múltiplos. Anais do VI Simpósio Brasileiro de Hidrologia e Recursos Hídricos, 4: 38-59.

TUNDISI, J. G., 1986, The Lobo (Broa) ecosystem. Ciência Interamericana, 25(1/4): 18-31.

UTERMÖHL, H., 1958, Zur vervollkommung der quantitativen phytoplankton-methodik. Mitt. Int. Verein. Theor. Angew. Limnol., 9: 1-38.

VOLLENWEIDER, R. A. (ed.), 1974, A manual on methods for measuring primary production in aquatic environments. IBP no 12, 2a ed., Blackwell Sci. Publ., 213p. 